\title{
El riesgo operacional en la nueva Ley de Contratos del Sector Público
}

\author{
Alejandro Huergo Lora \\ Universidad de Oviedo \\ ahuergo@uniovi.es
}

\begin{abstract}
NOTA BIOGRÁFICA
Alejandro Huergo Lora es Catedrático de Derecho Administrativo de la Universidad de Oviedo. Doctor en Derecho por la Universidad de Bolonia. Sus líneas de investigación se centran en el contencioso-administrativo, las sanciones administrativas y los contratos públicos.
\end{abstract}

\section{SUMARIO}

1. INTRODUCCIÓN. 2. LAS CLÁUSULAS CONTRACTUALES DE REPARTO DE RIESGOS. 3. EL ALCANCE DE LA NOVEDAD LEGISLATIVA. 4. LOS ORÍGENES DE LA REGULACIÓN DEL RIESGO OPERACIONAL EN LA DIRECTIVA 2014/23/UE. a) EL INTENTO DEL TJ Y DE LA COMISIÓN DE EVITAR LA «HUIDA A LAS CONCESIONES». b) EL RIESGO CONCESIONAL EN LA NORMATIVA EUROPEA SOBRE CONTABILIDAD PÚBLICA (SEC-2010). 5. LA REGULACIÓN DEL RIESGO OPERACIONAL EN LA DIRECTIVA 2014/23. 6. EL RIESGO OPERACIONAL EN LA NUEVA LCSP DE 2017. 7. DUDAS Y CUESTIONES ABIERTAS.

\section{INTRODUCCIÓN}

Una de las novedades más destacadas de la Ley 9/2017, de 8 de noviembre, de Contratos del Sector Público, por la que se transponen al ordenamiento jurídico español las Directivas del Parlamento Europeo y del Consejo 2014/23/UE y 2014/24/UE, de 26 de febrero de 2014, es la introducción del concepto de «riesgo operacional», que se erige en condición sine que non de las concesiones de obras y servicios ${ }^{1}$. Si el concesionario no asume ese «riesgo operacional», el contrato no será una auténtica concesión sino un tipo contractual diferente -concretamente un contrato de obras o de servicios, respectivamente ${ }^{2}$. Vaya por delante el recordatorio de que la concesión de obras o de servicios es un contrato más, como recuerda la propia Directiva 2014/23/UE desde su mismo título (Directiva «relativa a la adjudicación de contratos de concesión»), por lo que no deben llevar a equívoco algunas expresiones de fuentes comunitarias, que contraponen «concesiones» y «contratos públicos».

\footnotetext{
1 Agradezco a los profesores Santiago Muñoz Machado y Mariano López Benítez la invitación a participar en la edición de 2017 del Seminario sobre la Reforma del Estado, que tuvo lugar en Madrid el 18 de octubre, en la que expuse las ideas recogidas en este trabajo. Una versión muy simplificada e inicial de las mismas se dio a conocer en el seminario de Estudio Jurídico lus Publicum, celebrado también en Madrid el 6 de abril de 2017. Agradezco las observaciones de los profesores Juan Mestre Delgado, Andrés Betancor Rodríguez, Vicente Álvarez García, Eva Desdentado Daroca y Juan Antonio Carrillo Donaire.

Por otro lado, esta publicación se enmarca en la actividad del Grupo de Investigación «Derecho Administrativo» de la Universidad de Oviedo, y en los proyectos de investigación FC-15-GRUPIN14-039, financiado por el Principado de Asturias (Consejería de Economía y Empleo), y DER2014-59595-P, del Ministerio de Economía y Competitividad.

2 De entre los trabajos que, en lengua española, estudian el riesgo operacional en la Directiva 2014/23/UE y su incorporación al Derecho español, destaca el de A. ROMÁN MÁRQUEZ, "El riesgo en las concesiones de obras y servicios públicos: orígenes, evolución y situación actual en el ordenamiento jurídico comunitario”, REDA, 182 (2017), págs. 445-481.
} 
La concesión ya no se define ni se distingue de los contratos de obras o servicios por el hecho de tener por objeto una obra o un servicio públicos, ni por que el contratista reciba pagos directos de los usuarios o de la Administración. Por lo tanto, en algunos casos el contratista privado recibe en el contrato el derecho a explotar la obra o servicio, pero, como no asume ese «riesgo operacional», no nos hallamos ante una auténtica concesión sino ante un contrato de obra o de servicio. La concesión (de obra o de servicio) ya no se define sólo por la forma de remuneración del contratista, sino que se exige expresamente que éste asuma el riesgo operacional.

La segunda consecuencia de esta novedad legislativa es que el concepto de servicio público pierde relevancia a la hora de clasificar el contrato. Hasta ahora, cuando el contrato tenía por objeto un servicio público el intérprete se dirigía al contrato de gestión de servicios públicos en sus diversas modalidades, una de las cuales es precisamente la concesión.

En la nueva Ley, en cambio, los contratos que tienen por objeto «servicios» (públicos o no), serán concesiones de servicios o contratos de servicios en función de la asunción por parte del contratista, o no, del riesgo operacional. La distinción entre contrato y concesión no está alineada con la distinción entre servicios públicos y servicios de otra naturaleza, sino que se cruza con ella, de modo que tanto las concesiones como los contratos de servicios pueden tener por objeto cualquier tipo de servicios, tanto públicos como de otro tipo. Surgen, así, cuatro posibilidades reguladas en la propia Ley: concesiones de servicios públicos y de servicios «ordinarios», y contratos de servicios «no públicos» y contratos de servicios que tienen por objeto un servicio público.

En las páginas que siguen, partiremos del significado que tienen las cláusulas de reparto de los riesgos en la contratación en general y en la contratación pública en particular. Después se comprobará hasta qué punto estas novedades de la LCSP constituyen una novedad real, para examinar a continuación su origen, es decir, las fuentes de la regulación contenida en la Directiva 2014/23/UE. A continuación estudiaremos la normativa establecida en la recién aprobada LCSP, para contemplar, finalmente, las cuestiones abiertas y la valoración general de este cambio legislativo.

\section{LAS CLÁUSULAS CONTRACTUALES DE REPARTO DE RIESGOS}

Las normas que establecen que en las concesiones de obras o de servicios el concesionario tiene que asumir «un riesgo operacional» (artículos 14.4 y 15.2, entre otros) son normas legales imperativas que exigen, para que un contrato sea clasificado como concesión y se le aplique el régimen legalmente previsto para ese contrato, que el contratista privado asuma en una determinada medida ese «riesgo operacional».

Aunque hasta ahora no se definía expresamente ningún tipo contractual en función de la asunción de riesgos, las normas legales y las cláusulas contractuales de atribución o de reparto de riesgos entre las partes del contrato son muy frecuentes tanto en la contratación en general como en los contratos públicos. Y es que el contenido de un contrato se define no sólo por las obligaciones asumidas por las partes (y los correlativos derechos atribuidos a las mismas), sino también por la medida en que cada una de ellas asume los riesgos derivados del contrato, o los comparte. Como dice Á. CARRASCO, «[t]odo contrato se halla expuesto en mayor o menor medida a que fracasen, por razones no imputables a la conducta o a la previsión de las partes, las expectativas y los intereses que los contratantes han querido satisfacer con la celebración de aquél». «[E]l fracaso del contrato es una contingencia sobrevenida que afecta en todo o en parte a la rentabilidad esperada por los contratantes. El riesgo contractual es la posibilidad de este fracaso, y las técnicas de imputación del riesgo constituyen los mecanismos diseñados por las partes, o supletoriamente por la ley, para asignar a una, o ambas, de las partes el efecto perjudicial de la contingencia del fracaso» ${ }^{3}$.

En el derecho contractual general existen reglas de reparto o de atribución de riesgos como res perit domino, periculum emptoris, periculum debitoris, el efecto liberatorio de la fuerza mayor y en determinados casos del caso fortuito (artículo 1105 CC), la regla rebus sic stantibus, etc. En unos casos se trata de normas legales (algunas de ellas imperativas, otras dispositivas). Pero también pueden introducirse en los contratos (y se hace con frecuencia) cláusulas de atribución y de distribución del riesgo. Por ejemplo, los contratos «llave en mano» (EPC) se definen por la asunción de determinados riesgos por parte del contratista, en comparación con, por ejemplo, un contrato de obra ordinario.

3 Á. CARRASCo PERERA, Derecho de contratos, Aranzadi, Cizur Menor, 2010, pág. 963. Sobre la distribución de riesgos, vid. págs. 963-1.045, extraordinariamente ilustrativas. 
También en el ámbito de la contratación administrativa encontramos reglas legales de atribución de riesgos, empezando el «principio de riesgo y ventura» (artículo 197 LCSP), que afecta a todos los contratos administrativos. Lo mismo cabe decir del derecho del contratista a ser indemnizado en casos de fuerza mayor (artículo 239), que es una regla aplicable exclusivamente el contrato de obras ${ }^{4}$. La "cláusula de progreso» de las concesiones (artículo 259.4) también atribuye al concesionario un riesgo, el del incremento de la onerosidad del contrato como consecuencia de la necesidad de implantar novedades derivadas del progreso de la ciencia o de «la normativa técnica, medioambiental, de accesibilidad y eliminación de barreras y de seguridad de los usuarios», aunque la nueva Ley limita ese riesgo con una facultad de desistimiento del concesionario en caso de que «el concesionario deba incorporar, por venir obligado a ello legal o contractualmente, a las obras o a su explotación avances técnicos que las mejoren notoriamente y cuya disponibilidad en el mercado, de acuerdo con el estado de la técnica, se haya producido con posterioridad a la formalización del contrato» [artículo 270.4.b)] . Otro ejemplo es el derecho del concesionario al restablecimiento del equilibrio financiero del contrato ante situaciones de «riesgo imprevisible», actualmente no reconocido expresamente por la legislación de contratos públicos pero que encontraba acogida en el artículo 127.2.2. ${ }^{\circ}$ b) del RSCL ( «La Corporación concedente deberá (...) mantener el equilibrio financiero de la concesión, para lo cual (...) revisará las tarifas y subvención cuando, aun sin mediar modificaciones en el servicio, circunstancias sobrevenidas e imprevisibles determinaren, en cualquier sentido, la ruptura de la economía de la concesión»).

Este es el contexto en el que deben situarse los preceptos que exigen que, en los contratos de concesión (de obras o de servicios), el concesionario asuma un riesgo operacional.

\section{EL ALCANCE DE LA NOVEDAD LEGISLATIVA}

Aunque en el TRLCSP (aprobado por Real Decreto Legislativo 3/2011, de 14 de noviembre) no utilizaba la expresión «riesgo operacional», sí contenía referencias expresas al riesgo como un requisito imprescindible en las concesiones de obras y de servicios.

En el caso de las concesiones de obra, el artículo 7.2 del TRLCSP decía que este contrato «se ejecutará en todo caso a riesgo y ventura del contratista», lo que no era decir mucho porque el principio de riesgo y ventura era de aplicación a todos los contratos administrativos en virtud del artículo 215. Pero la mención expresa al riesgo y ventura en el artículo 7.2 se entiende mejor a la luz de la Exposición de Motivos de la Ley 13/2003, de 23 de mayo, reguladora del contrato de concesión de obras públicas, cuyo contenido pasó, sin modificación alguna, al TRLCSP de 2011, para sufrir después cambios importantes por obra de la Ley 40/2015. En ella se insiste en la necesidad de que «el concesionario asuma el riesgo de su construcción, conservación y explotación ${ }^{6}$, no sólo por razones de tutela del interés público, sino para cumplir las exigencias del Derecho europeo, que entonces no estaban recogidas expresamente en ninguna norma, pero que se desprendían del texto de las Directivas entonces vigentes, como decía una Comunicación interpretativa de la Comisión y poco después establecería el TJ en su jurisprudencia, tal como veremos en el siguiente epígrafe ${ }^{7}$.

Por lo que respecta a la concesión de servicios, el artículo 277.a) del TRLCSP disponía que, dentro de las distintas modalidades del contrato de gestión de servicios públicos, lo que caracteriza a la concesión es el dato de que «el empresario gestionará el servicio a su propio riesgo y ventura». Algo que venían diciendo

\footnotetext{
${ }^{4}$ El trabajo clásico de E. GARCÍA DE ENTERRÍA, “Riesgo y ventura y fuerza mayor en el contrato administrativo”, RAP, 2 (1950), págs. 83-108, explica magníficamente cómo encaja el "principio de riesgo y ventura» en la distribución de riesgos del Derecho de contratos.

${ }^{5}$ Sobre la cláusula de progreso, vid. por todos, J. L. MEILÁN GIL, La cláusula de progreso en los servicios públicos, IEA, Madrid, 1968 y T. QUINTANA LÓPEZ, "Algunas cuestiones sobre la cláusula de progreso en el contrato de concesión de obras públicas", REDA, 131 (2006), págs. 421-444.

${ }_{6}$ «Reviste importancia capital, para que la concesión de la obra pública conserve sus señas de identidad y pueda ser reconocida como tal, que el concesionario asuma el riesgo de su construcción, conservación y explotación. Evidentemente, en un contrato de larga duración por naturaleza, la asunción del riesgo, ante la imposibilidad de predecir con un margen razonable de error el futuro, no puede transformar el contrato en un negocio aleatorio por lo que en coherencia se impone moderar adecuadamente los límites del riesgo, si se quieren atraer la participación del capital y la iniciativa privadas en inversiones cuyo volumen exige el esfuerzo compartido de los sectores público y privado. Debe destacarse, sin embargo, que la asunción de riesgo en "proporción sustancial" por el concesionario resulta determinante para que el contrato de concesión merezca tal calificación. La ley responde así, sin ambigüedades, a las exigencias de la doctrina y conclusiones de la Comisión Europea, expuestas en su Comunicación Interpretativa 2000/C 121/02, publicada en el Diario Oficial de la Comunidad Europea de 29 de abril de 2000. Esta doctrina del riesgo informa en consecuencia la regulación que la ley hace de la concesión de obras públicas».

7 Comunicación Interpretativa 2000/C 121/02, publicada en el Diario Oficial de la Comunidad Europea de 29 de abril de 2000.
} 
las normas precedentes, como el artículo 134.3 del RSCL, o el artículo 66 del Texto Articulado de la Ley de Bases de Contratos del Estado (aprobado por Decreto 923/1965, de 8 de abril). Aquí no estamos hablando del principio general de riesgo y ventura, aplicable a todos los contratos administrativos, sino de algo característico de la concesión de servicios que la distingue de otras modalidades del contrato de gestión de servicios públicos.

Lo cierto es que, pese a la claridad de estas normas, en España se plantearon dudas acerca de la correcta calificación de determinados contratos, que parecían oscilar entre la concesión de servicios públicos y el contrato de servicios. Con frecuencia, las Administraciones intentaron calificar como concesiones de servicios determinados contratos que tenían por objeto la gestión indirecta de un servicio público, pero en los que era dudoso que el concesionario asumiera el «riesgo y ventura del servicio». Múltiples informes de los órganos consultivos de contratación pública y de los de resolución de recursos ${ }^{8}$ e incluso alguna sentencia del TJ ${ }^{9}$ dejaron claro que sólo hay concesión de servicios cuando el concesionario asume el riesgo y ventura del servicio, y que cuando no se produce esa asunción del riesgo, el contrato no puede ser calificado como concesión de servicios públicos (sino como contrato de servicios), por mucho que se refiera a la gestión de un servicio público ${ }^{10}$. Quede claro que no está en juego la legalidad del contrato, sino su calificación. Son admisibles fórmulas de colaboración en las que el contratista no asuma el riesgo y ventura del servicio, pero recibirán la calificación de contrato de servicios y no la de concesión de servicios.

¿Qué diferencias concretas de régimen jurídico existían entre la concesión de servicios y el contrato de servicios? En el caso español (y antes de la LCSP de 2017), la diferencia más destacada era el plazo, mucho más largo en las concesiones ${ }^{11}$. La concesión, aun estando sometida a los mismos procedimientos de licitación que los contratos de servicios ( $\mathrm{y}$ en ese sentido era tan difícil conseguir una concesión como un contrato de servicios), proporcionaba al contratista una posición mucho más sólida en cuanto más duradera. En muchos casos se pudo, incluso, prolongar la relación contractual (y, en consecuencia, la obtención de ingresos) sin licitación, a cambio de la realización de determinadas inversiones por parte del concesionario, pactadas con la Administración, a través de fórmulas de "restablecimiento del equilibrio financiero» mediante la prórroga del contrato, que fueron expresamente admitidas durante los años 90 en el ámbito de las concesiones de obras (autopistas de peaje) ${ }^{12}$. También hay que destacar que la cuantía necesaria para aplicar el recurso especial en materia de contratación era mucho más baja en los contratos de servicios que en las concesiones ${ }^{13}$.

Las confusiones entre ambos tipos contractuales surgen porque las concesiones pueden definirse por tres características diferentes, que normalmente coinciden, pero no siempre. La primera es que la remuneración del concesionario es un peaje o tarifa por la utilización de la obra o la prestación del servicio (normalmente abonado por los usuarios, aunque también puede hacerlo la Administración) y no un pago efectuado por la Administración en función de la actividad desplegada por el contratista. La segunda (referida a las concesiones de servicios) es que tengan por objeto la gestión indirecta de un servicio público. Y la tercera es la asunción del riesgo y ventura por parte del contratista. Lo que se afirmó en todos esos casos dudosos (y veremos que ése es el núcleo de la jurisprudencia del TJ) es que el concepto de concesión exige la asunción por el concesionario del «riesgo» (dejemos los matices por ahora: riesgo y ventura, riesgo operacional, riesgo de explotación, riesgo de gestión), no siendo suficientes otras notas que en realidad son total o parcialmente contingentes, como la forma de remuneración o la naturaleza jurídico-pública de la obra o servicio gestionados por el concesionario.

\footnotetext{
8 Por poner un ejemplo reciente, ejemplo, resolución del TACRC sobre contrato del Ayuntamiento de Candamo para residencia de ancianos (Recurso núm. 438/2015 C. A. Principado de Asturias 30/2015, Resolución núm. 543/2015). Una exposición detallada de esa doctrina puede verse en D. SANZ PÉREZ/M. REVERTER BAQUER, "La Directiva de concesiones: Especial atención al riesgo operacional y su aplicación práctica en nuestro ordenamiento", en M. Á. RECUERDA GIRELA (dir.), Problemas prácticos y actualidad del Derecho Administrativo. Anuario de Derecho Administrativo 2016, Civitas, Cizur Menor, 2016, págs. 421-446.

9 Sentencia de 27 de octubre de 2005 (asunto C-158/03, Comisión contra España, párrafo 32).

10 Lo estudia con abundante bibliografía RAZQUIN LIZARRAGA, M. M., "Contratos de gestión de servicios públicos y recursos especiales en materia de contratación (presente y propuestas de reforma)", REDA, 161 (2014), págs. 37-74.

11 Basta comparar, en el TRLCSP, los artículos 303 (contratos de servicios: 4 años más otros 2 de prórroga) y 278 (concesiones de servicios públicos: 50-20-10 años, respectivamente, para concesiones con construcción de obras, de mera explotación y de mera explotación de servicios sanitarios).

12 Art. 157 de la Ley 13/1996, de 30 de diciembre.

${ }_{13}$ De acuerdo con el artículo 40 del TRLCSP, en los contratos de servicios el recurso especial en materia de contratación se puede presentar a partir de un umbral situado entre 134.000 y 207.000 euros (según el tipo de servicio), mientras que en las concesiones de servicios hace falta que el plazo sea superior a 5 años y que el presupuesto de gastos de primer establecimiento supere los 500.000 euros.
} 
También debe subrayarse desde ahora el equívoco que puede surgir entre el «principio de riesgo y ventura», como exigencia de todos los contratos administrativos, y la asunción del «riesgo y ventura del servicio», como exigencia específica de las concesiones de servicios (y de las de obras), en las que se redobla la exigencia de la asunción del riesgo y ventura, que ya es un principio general de todos los contratos administrativos. ¿En qué consiste ese «riesgo y ventura del servicio» que va más allá del «principio de riesgo y ventura», hasta el extremo de que hay contratos en los que se aplica el segundo, pero no el primero?

En todo caso, lo que interesa destacar como conclusión de este epígrafe es que la asunción del riesgo por el concesionario es una regla que ya se aplicaba en nuestro Ordenamiento jurídico, y no sólo por imposición del Derecho comunitario sino por sus propias normas. En este sentido, puede ocurrir (es una hipótesis que trataré de argumentar a lo largo del trabajo) que la novedad que incorporan tanto la Directiva 2014/23/ UE como la nueva LCSP sea precisamente una reducción del nivel de riesgo que debe asumir el concesionario para que el contrato pueda recibir la calificación de concesión de obras o de servicios.

\section{LOS ORÍGENES DE LA REGULACIÓN DEL RIESGO OPERACIONAL EN LA DIRECTIVA 2014/23/UE}

La Directiva 2014/23/UE, que es la fuente directa de la nueva LCSP, tiene, a su vez, su origen -en lo que respecta al riesgo operacional- en dos conceptos de riesgo que surgieron de forma paralela e independiente en el Derecho comunitario: la jurisprudencia del TJ sobre la definición de las concesiones de obras y servicios (con la que se quería evitar la huida de las normas sobre licitación de los contratos públicos, que no eran exigibles en la adjudicación de concesiones) y la normativa contable de la UE (aprobada mediante sucesivos Reglamentos comunitarios, el último de ellos de 2013) con la que se persigue garantizar la transparencia de las cuentas públicas de los Estados miembros y la credibilidad de sus cifras de déficit y deuda pública. Esta normativa también define el riesgo como elemento esencial de las concesiones, en el intento de evitar que los Estados miembros camuflen los compromisos financieros que asumen, mediante una inadecuada calificación de los mismos como concesión.

Vamos a ver por separado ambas fuentes, porque es necesario para entender el texto de la Directiva, que constituye una curiosa mezcla que no se ajusta exactamente a las reglas que hasta ese momento venían aplicándose en el Derecho europeo de los contratos públicos.

\section{a) El intento del TJ y de la Comisión de evitar la «huida a las concesiones»}

Las Directivas de contratos públicos de los años 90 y las de 2004 se aplicaban a los contratos de obras, suministros y servicios, pero no a las concesiones. Se definían las concesiones de obras, pero su adjudicación no se sometía a las reglas aplicables a los contratos de obras ${ }^{14}$. Lo único que se regulaba era la obligación de que el concesionario de obras aplicara ciertas normas de publicidad en la selección de sus subcontratistas. Las concesiones de servicios, no mencionadas en las Directivas de los años 90, son definidas y expresamente excluidas del ámbito de aplicación de la Directiva 2004/18/CE ${ }^{15}$. Tampoco se aplicaba

14 La Directiva 93/37/CEE, de 14 de junio de 1993, sobre coordinación de los procedimientos de adjudicación de los contratos públicos de obras, define la concesión de obras públicas como el contrato que «presente los caracteres» del contrato de obras (es decir, su mismo objeto), «con la salvedad de que la contrapartida de las obras consista, o bien únicamente en el derecho a explotar la obra, o bien en dicho derecho acompañado de un precio». El artículo 3 determina las normas de publicidad aplicables a las concesiones que superen el umbral económico fijado, así como a las subcontratas.

La Directiva 2004/18/CE, que se refiere a los procedimientos de adjudicación de los contratos de obras, suministros y servicios, define la concesión de obras en idénticos términos (art. 1.3) y establece normas de publicidad similares a las de la Directiva anterior, aunque más detalladas (artículos 56-65).

15 No mencionaba las concesiones de servicios la Directiva 92/50/CEE, de 18 de junio de 1992, sobre coordinación de los procedimientos de adjudicación de los contratos públicos de servicios.

Artículo 1.4 de la Directiva 2004/18/CEE: «La "concesión de servicios" es un contrato que presente las mismas características que el contrato público de servicios, con la salvedad de que la contrapartida de la prestación de servicios consista, o bien únicamente en el derecho a explotar el servicio, o bien en dicho derecho acompañado de un precio". Artículo 17: "Sin perjuicio de la aplicación de las disposiciones previstas en el artículo 3, la presente Directiva no será aplicable a las concesiones de servicios definidas en el apartado 4 del artículo 1". El artículo 3 dispone que "[C[uando un poder adjudicador otorgue derechos especiales o exclusivos para el ejercicio de una actividad de servicio público a una entidad distinta de dicho poder adjudicador, el acto por el que se otorgue dicho derecho impondrá a la entidad en cuestión, en los contratos de suministro que adjudique a terceros en el marco de esa actividad, la obligación de respetar el principio de no discriminación por razones de nacionalidad"». 
a las concesiones la Directiva de recursos ${ }^{16}$. Los Estados miembros podían adjudicar las concesiones (de forma especialmente clara en el caso de las de servicios) sin sujetarse a los procedimientos de licitación regulados en las Directivas, aunque ciertamente era aplicable el Derecho comunitario primario (las exigencias genéricas derivadas de las libertades comunitarias reguladas en los Tratados), en los términos establecidos por la jurisprudencia del TJ.

En España el legislador no aprovechó esa «libertad» que le concedía el legislador comunitario para permitir que las concesiones se adjudicasen con mucho menores requisitos de publicidad. Al contrario, la adjudicación de las concesiones venía sometida, desde antes de la aplicación del Derecho comunitario en España, a las mismas reglas aplicables a la adjudicación de los demás contratos típicos (obras, suministros, servicios). Sí es verdad que, como hemos visto, las concesiones tenían un plazo de duración más largo, lo que las convertía en una fórmula preferible para muchas empresas y también para determinadas Administraciones, entre otras cosas porque ese plazo largo permitía obtener un elevado «canon concesional» liquidable en el momento de perfección del contrato ${ }^{17}$.

En otros Estados miembros, singularmente Alemania, sí que había una fuerte oposición, sobre todo por las Administraciones locales, a someter a los procedimientos de licitación fórmulas jurídicas que se venían utilizando para la gestión de los servicios públicos ${ }^{18}$. Estamos hablando sobre todo de mecanismos de colaboración interadministrativa o de empresas mixtas, o de fórmulas de colaboración con entidades sin ánimo de lucro para la gestión de servicios sociales. Técnicas que no pueden subsistir si la Administración se ve obligada a someter los correspondientes contratos a una licitación abierta. Las Directivas 2014/23 y 2014/24 contienen preceptos que dan un cierto encaje a este tipo de fórmulas, pero inicialmente era el concepto de concesión el refugio que buscaban las entidades que querían persistir en la utilización de tales fórmulas jurídicas ${ }^{19}$.

Aunque el Tribunal de Justicia ha declarado en varias sentencias, estimando recursos interpuestos por la Comisión, que España ha incumplido las obligaciones que le impone el Derecho comunitario en materia de contratación pública, y otras sentencias, resultado de cuestiones prejudiciales, también han puesto de manifiesto desajustes entre nuestra legislación y las Directivas, la actitud de la doctrina española es muy receptiva hacia la legislación comunitaria y la jurisprudencia del TJ, cuya recta incorporación al Derecho español es el máximo objetivo de la doctrina ${ }^{20}$. En cambio, en Alemania ha habido una importante resistencia al Derecho comunitario de la contratación. Primero, para mantener la política tradicional de que la contratación pública fuera una oportunidad para el denominado Mittelstand (equivalente aproximadamente a las PYMES y una fuerza muy potente en la economía alemana, con gran peso político). La tendencia a dividir los contratos en lotes correspondientes a los distintos oficios, para permitir que las empresas especializadas puedan acceder a contratos de las Administraciones en lugar de verse convertidas en subcontratistas de las grandes constructoras (que es lo que sucede normalmente en España), llevó a Alemania a boicotear la tutela judicial frente a las decisiones administrativas de licitación y adjudicación de contratos, tanto antes como después de la aprobación de la Directiva de recursos ${ }^{21}$. Éste es el verdadero trasfondo de una discu-

16 La Directivas 89/665/CEE, de 21 de diciembre de 1989, «relativa a la coordinación de las disposiciones legales, reglamentarias y administrativas referidas a la aplicación de los procedimientos de recurso en materia de adjudicación de los contratos públicos de suministros y de obras» no incluía la adjudicación de las concesiones de obra, que en aquel momento ni siquiera eran aludidas en la Directiva sustantiva. Con la reforma introducida por la Directiva 2007/66/CE, de 11 de diciembre de 2007, ya se incluían las concesiones de obras (artículo 1.1), aunque únicamente para hacer cumplir las limitadas normas establecidas en la Directiva 2004/18.

17 En un plano no estrictamente jurídico, es innegable que la concesión de servicios está «sobrerrepresentada» en los casos de corrupción que han llegado a la jurisdicción penal. La búsqueda de ese «canon concesional», que permite a un responsable político, el que ocupe el órgano adjudicador en el momento en que se licita y adjudica el contrato, gastar una importante cantidad de recursos (con la correspondiente rentabilidad electoral) que se va a generar a lo largo de un largo plazo concesional, está muy alejada de los criterios de buen gobierno.

18 Vid. M. BURGI, Vergaberecht. Systematische Darstellung für Praxis und Ausbildung, Beck, München, 2016, págs. 263-264. El principal efecto de la Directiva es obligar a licitar las concesiones de servicios: K. WILLENBRUCH, en WILLENBRUCH/WIEDDEKIND, Vergaberecht, Werner Verlag, Köln, 2017 (4. a ed.), pág. 112.

19 En particular sobre la atención especial a los contratos públicos en materia de servicios sociales en las nuevas Directivas, vid. M. ÁLVAREZ FERNÁNDEZ, "La colaboración privada en la gestión de servicios sociales públicos. La incidencia de las nuevas directivas de contratación y su transposición al ordenamiento jurídico español”, REDA, 172 (2015), págs. 317-362.

${ }_{20}$ Critica esa actitud J. SANTAMARÍA PASTOR, "Contratos del sector público y Derecho de la Unión", RAP, 200 (2016), págs. 83102 (pág. 95: «la doctrina español, a la que caracteriza habitualmente un encendido tono hagiográfico hacia dichas regulaciones»), 0 "La constante e interminable reforma de la normativa sobre contratación pública", REDA, 159 (2013), págs. 25-38.

21 Traté de contar este episodio en "La nueva regulación de los contratos públicos en Alemania. Reflexiones desde el derecho español", en el EI Derecho Administrativo en el umbral del siglo XXI. Homenaje al Prof. Dr. don Ramón Martín Mateo, Editorial Tirant lo Blanch, Valencia, 2000, vol. II, págs. 1.841-1.878. 
sión en la que entran en juego figuras dogmáticas como el derecho público subjetivo. La Directiva 2014/24 cede ante esta vieja preocupación alemana, al admitir el «fraccionamiento» del contrato en lotes (no confundir con el fraccionamiento como mecanismo fraudulento para eludir la superación de los umbrales que obligan a tramitar procedimientos públicos de licitación, a base de dividir el contrato en varios contratos menores o, en su momento, en varios contratos que pudieran adjudicarse por el procedimiento negociado sin publicidad) ${ }^{22}$. La Directiva contempla esa técnica como una facultad de los Estados miembros (dirigida, obviamente, a satisfacer a los que tienen esa preocupación, como ocurre justamente con Alemania), que en España ha sido acogida con cierta amplitud por el legislador, en lo que supone una novedad cuyos resultados están todavía por ver.

La Directiva de concesiones (2014/23), que por primera vez somete la licitación y adjudicación de todas las concesiones a un procedimiento público (aunque mucho menos exigente que el que se aplica a los contratos, regulado en la Directiva 2014/24) despertó una gran resistencia en Alemania, concretamente en los Länder, en los que se integran las entidades locales cuya importante participación en la gestión de los servicios públicos se ponía en cuestión. De hecho, el Bundesrat o cámara territorial (figura constantemente citada entre nosotros en los debates sobre la posible reforma constitucional) puso en marcha (obviamente en vano), el mecanismo previsto en el Protocolo núm. 2 al TUE, «sobre la aplicación de los principios de subsidiariedad y proporcionalidad», para oponerse a la propuesta de Directiva ${ }^{23}$. Una protesta a la que también se unió nuestro Congreso de los Diputados, aunque se haya olvidado de ello en el procedimiento de elaboración de la LCSP ${ }^{24}$.

Esta especie de «oposición con buena conciencia» a las Directivas, que contrasta con la vergonzante resistencia a su cumplimiento que entre nosotros se ha registrado con alguna frecuencia, es capitaneada, como estamos viendo, por el mundo de los entes locales (en el caso concreto de las concesiones) y por los órganos con competencia en materia de empresa y fomento de la economía (en lo que se refiere al apoyo del Mittelstand). La fórmula concreta que se estableció en su momento para el cumplimiento de la Directiva de recursos fue un recurso ante órganos integrados en las autoridades de defensa de la competencia, con posibilidad de acudir finalmente a los tribunales civiles que son competentes en asuntos de defensa de la competencia (el equivalente a nuestras secciones de lo mercantil de las Audiencias Provinciales). Los encargados de hacer cumplir las Directivas no son, por tanto, y a diferencia de lo que sucede en España, los tribunales contencioso-administrativos, sino los civiles (mercantiles), lo que favorece que la doctrina más "procomunitaria» sea la mercantil o de la competencia, mientras que en el sector administrativista se tiende a tener en cuenta las peculiaridades o exigencias de las instituciones jurídico-administrativas ${ }^{25}$.

22 Conviene tener en cuenta que cuando en los años 90 se pone en marcha la nueva generación de Directivas sobre contratos públicos y en particular las de recursos (acompañadas de la puesta en práctica de otras normas europeas que también se aplicaban a los grandes proyectos de obras, como las relativas a la evaluación de impacto ambiental), la dotación de infraestructuras era mucho más alta en Alemania que en España (salvo en los Länder de la antigua República Democrática de Alemania). No se puede analizar la aplicación de las normas europeas en los distintos Estados miembros sin tener en cuenta que Alemania era un país "ya construido», mientras que España era una país «en construcción», que en esa década (fondos de cohesión) y en la siguiente (burbuja inmobiliaria) tramitó, adjudicó y ejecutó una ingente cantidad de obras. Quiero decir con ello que una misma normativa puede resultar más difícil de aplicar con rigor en un país sometido a un fuerte impulso inversor que en otro en el que las grandes obras resultan excepcionales. De los problemas que surgen también en Alemania al gestionar grandes obras públicas da fe la desastrosa peripecia de la construcción del nuevo aeropuerto de Berlín. Por otro lado, y desde una perspectiva jurídica, cuando allí fue necesario realizar grandes obras en poco tiempo (es decir, en los años posteriores a la reunificación) se utilizaron técnicas como la aprobación mediante Ley de proyectos de obras (y de expropiación) para evitar las posibilidades de que su ejecución fuera paralizada por recursos de los afectados. Una técnica que fue admitida por su Tribunal Constitucional (decisión de 17 de julio de 1996, BVerfGE, 95, 1) y que es similar a la utilizada en España en varios casos durante la década de los 2000 y que fue declarada inconstitucional en varias ocasiones (STC 203/2013).

${ }^{23}$ Vid. M. BURGI, Vergaberecht, cit., pág. 264, nota 10, y M. OPITZ, "Die Zukunft der Dienstleistungskonzession”, NVwZ, 2014, págs. 753-760, esp. págs. 753-754.

24 En el BOCG, Serie A, número 24, de 14 de marzo de 2012, se publica el Dictamen motivado 1/2012 de la Comisión Mixta para la Unión Europea sobre el incumplimiento del principio de subsidiariedad por la propuesta de Directiva del Parlamento Europeo y del Consejo relativa a la adjudicación de contratos de concesión, basado, entre otras cosas, en que «lo que la propuesta [de Directiva] identifica como un problema no es más que la realidad jurídica y cultural diversa de los países que forman la Unión, que debe ser objeto de respeto en tanto en cuanto no suponga una auténtica barrera al mercado, aspecto este que está lejos de quedar acreditado».

25 Sobre ese reparto de papeles, M. BURGI, Vergaberecht, cit., págs. 263-264. En Alemania las resoluciones dictadas por las autoridades de defensa de la competencia son recurribles ante la jurisdicción civil, no ante la contencioso-administrativa. Los jueces y tribunales civiles conocen, por tanto, de la defensa de competencia en sentido global, tanto desde el punto de vista jurídico-privado como jurídico-público. Vid. mi trabajo "Derecho de la competencia. Cooperación y concurrencia entre autoridades administrativas y tribunales", en Memorial para la reforma del Estado. Estudios en homenaje al profesor Santiago Muñoz Machado (coordinado por el profesor José María BAÑO LEÓN), CEPC, Madrid, 2016, vol. III, págs. 2.283-2.312, pág. 2.295, nota 24. 
Con esta explicación es fácil entender, creo, el sentido de la jurisprudencia del TJ que va aclarando qué se entiende por concesión y qué es un contrato público distinto de una concesión (sabiendo que la consecuencia es el sometimiento íntegro a la Directiva, si el contrato no es una concesión).

Recordemos que el punto de partida normativo son los preceptos que, tanto en la Directiva 93/37 (concesión de obra), como en las Directivas 2004/17 y 2004/18 (concesiones de servicios) definen la concesión como «un contrato que presente las mismas características que el contrato de servicios, con la salvedad de que la contrapartida de la prestación de servicios consista, bien únicamente en el derecho a explotar el servicio, bien en dicho derecho acompañado de un pago» [artículo 1.3.b) de la Directiva 2004/17]. Pues bien, a partir de una sentencia de 13 de octubre de 2005, el TJ llega a la conclusión de que esa forma de remuneración, consistente en asumir el derecho a explotar el servicio, supone que el concesionario asume también el «riesgo de explotación» del servicio, lo que en ese contexto parece incluir claramente el denominado «riesgo de demanda», es decir, el riesgo de que el número de usuarios sea más o menos alto, lo que afectará a los ingresos del concesionario y por tanto a las posibilidades de recuperar la inversión efectuada ${ }^{26}$. Esa misma regla (la concesión no supone sólo una forma de remuneración, sino que conlleva la asunción por el concesionario del riesgo relacionado con la explotación de la obra o servicio) se repite en dos sentencias que estiman otros tantos recursos por incumplimiento presentados por la Comisión contra Italia, por haber adjudicado sin respetar la Directiva dos supuestas «concesiones» en las que en realidad el concesionario no asumía el riesgo, una de 18 de julio de 2007 (incineradoras de Sicilia) ${ }^{27}$ y otra de 13 de noviembre de $2008^{28}$ (tranvía de L'Aquila). Estas sentencias representan una doctrina «clásica» sobre la asunción del riesgo, que se exige que sea completa (asumir «el riesgo de explotación» de la obra o servicio objeto de concesión).

Los matices que finalmente recogerá la Directiva 2014/23 llegan con casos más recientes, procedentes sobre todo de Alemania y en los que es patente la presión para mantener bajo la etiqueta de «concesión» (y, por tanto, libre de los procedimientos de licitación de la Directiva) fórmulas de gestión de servicios en las que la asunción de riesgos es más limitada. Es lo que sucede en la sentencia de 10 de septiembre de 2009 (Eurawasser), referida a un servicio de abastecimiento de agua en el que el riesgo de explotación era mínimo ${ }^{29}$.

26 Sentencia Parking Brixen (13 de octubre de 2005, Sala Primera, C-458/03, cuestión prejudicial planteada por un tribunal administrativo de Bolzano): «la retribución del prestador de servicios no procede de la autoridad pública, sino de las cantidades abonadas por terceros para el uso del aparcamiento. Esta modalidad de retribución implica que el prestador asume el riesgo de explotación de los servicios, lo cual es una característica de la concesión de servicios públicos. Por consiguiente, la situación descrita en el litigio principal no se trata de un contrato público de servicios, sino de una concesión de servicios públicos» (párrafo 40). Recordemos que esta sentencia es importante en la construcción de la doctrina de los contratos in house.

${ }^{27}$ Sentencia Comisión c. Italia de 18 de julio de 2007 (incineración de residuos en Sicilia, Sala 2. ${ }^{\text {a }, ~ C-382 / 05): ~ « s e g u ́ n ~ l a ~ j u r i s p r u-~}$ dencia del Tribunal de Justicia, existe una concesión de servicios cuando la modalidad de retribución convenida consista en el derecho del prestador a explotar su propia prestación y suponga que éste asume el riesgo vinculado a la explotación de los servicios de que se trata (véanse la sentencia de 7 de diciembre de 2000, Telaustria y Telefonadress, C-324/98, Rec. p. l-10745, apartado 58, y el auto de 30 de mayo de 2002, Buchhändler-Vereinigung, C-358/00, Rec. p. I-4685, apartados 27 y 28, así como la sentencia Parking Brixen, antes citada, apartado 40)» (párrafo 34). Es interesante, por lo que luego se dirá, que esta sentencia considera que no existe asunción del riesgo cuando al concesionario se le garantiza una cantidad mínima de residuos a transferir o cuando se prevé que el canon se adapte en caso de que la cantidad de residuos supere o no llegue a un determinado umbral (párrafo 36).

${ }_{28}$ Sentencia Comisión c. Italia de 13 de noviembre de 2008 (tranvía de L’Aquila, Sala 3. a, C-437/07): se considera que constituye un contrato de obra (y no una concesión) un contrato en el que el «concesionario» construye la obra a cambio de recuperar el coste, en parte a través de un pago directo del «concedente» y en parte en unos pagos fijos a realizar por el prestador del servicio a lo largo de 30 años. No hay ningún riesgo de demanda, aunque puede que sí exista algo parecido al riesgo de disponibilidad.

${ }_{29}$ Sentencia Eurawasser (10-9-2009, Sala 3. ${ }^{a}$, C-206/08, cuestión prejudicial planteada por OLG de Thüringen). El mero hecho de que el contratista perciba la contraprestación de los usuarios del servicio, y no de la Administración, no es suficiente para que el contrato sea una auténtica concesión. Es preciso, además, «asumir el riesgo de explotación de los servicios»: «De la jurisprudencia del Tribunal de Justicia se desprende que, cuando la modalidad de retribución convenida consiste en el derecho del prestador a explotar su propia prestación, esta modalidad de retribución implica que el prestador asume el riesgo de explotación de los servicios (véanse, en este sentido las sentencias Parking Brixen, apartado 40; de 18 de julio de 2007, Comisión/Italia, apartado 34, y de 13 de noviembre de 2008, Comisión/Italia, apartado 29, antes citadas)» (párrafo 59). «El riesgo es inherente a la explotación económica del servicio» (párrafo 66). «Si la entidad adjudicadora sigue soportando la totalidad del riego sin exponer al prestatario a las incertidumbres del mercado, la atribución de la explotación del servicio requerirá la aplicación de las formalidades previstas por la Directiva 2004/14 para proteger la transparencia y la competencia» (párrafo 67). El problema que se planteaba en este caso es que el riesgo existente en el negocio era limitado (párrafos 72-73). EI TJ dice que eso no priva al poder adjudicador del derecho a utilizar la técnica de la concesión (párrafo 74), en una formulación que recuerda la idea de respeto a la autonomía organizativa de los Estados miembros, en la línea de la cooperación vertical y horizontal. Tampoco tiene sentido pedirle que cree un riesgo artificial para legitimar la concesión (párrafo 75). En conclusión, debe transferirse la totalidad y o una parte significativa del riesgo, sea éste poco o mucho: «incluso si el riesgo que corre la entidad adjudicadora es muy limitado, es necesario que transfiera al concesionario la totalidad, o al menos una parte significativa, del riesgo de explotación que corre para que se considere que existe una concesión de servicios» (párrafo 77). Se trata de una concepción «relativa», no «absoluta» del riesgo. Lo que no importa no es que sea poco o mucho, sino que se transfiera al concesionario. 
No es que la Administración concedente estuviera interesada en la adjudicación directa del contrato para favorecer a un particular; lo que estaba en juego era una fórmula de colaboración interadministrativa. En la siguiente sentencia, de 10 de marzo de 2011 (Privater Rettungsdienst), también procedente de Alemania, la discusión sobre el concepto de concesión también encubre el intento de salvar una técnica de gestión, en este caso la aplicación, en la contratación de los servicios sociales (en este caso, las ambulancias), de fórmulas no basadas estrictamente en el precio ${ }^{30}$. Las Directivas de 2014 atenderán esta preocupación estableciendo procedimientos más flexibles y umbrales más altos en este sector. En esta sentencia lo que hace el TJ es interpretar con generosidad el concepto de «riesgo de explotación», para aceptar que se produce su transmisión en un sector en el que el riesgo de demanda es mínimo o inexistente.

Esta última sentencia es muy importante porque perfila el riesgo que debe asumir el concesionario en unos términos que han pasado casi directamente a la Directiva 2014/23. Como no se trataba de una concesión al uso, en la que fuese obvio el riesgo asumido por el concesionario, era necesario desarrollar el concepto, como lo hace el Tribunal ${ }^{31}$. Ya no se habla de «riesgo de explotación del servicio» como de algo obvio (e identificado con el riesgo de explotación, incluido el de demanda), porque se está aplicando la concesión a servicios en los que el riesgo es pequeño. Pero debe existir un riesgo de que las cuentas salgan mal, de que el contrato resulte ruinoso:

«el riesgo de explotación económica del servicio debe entenderse como el riesgo de exposición a las incertidumbres del mercado (véase, en este sentido, la sentencia Eurawasser, antes citada, apartados 66 y 67), que puede traducirse en el riesgo de enfrentarse a la competencia de otros operadores, el riesgo de un desajuste entre la oferta y la demanda de los servicios, el riesgo de insolvencia de los deudores de los precios por los servicios prestados, el riesgo de que los ingresos no cubran íntegramente los gastos de explotación o incluso el riesgo de responsabilidad por un perjuicio causado por una irregularidad en la prestación del servicio (véanse, en este sentido, las sentencias de 27 de octubre de 2005, Contse y otros, C-234/03, Rec. p. I-9315, apartado 22, y Hans \& Christophorus Oymanns, antes citada, apartado 74).»

El Tribunal apunta en esta sentencia (y también esto pasará a la Directiva) que este riesgo del concesionario no debe confundirse con el riesgo que asume todo contratista (y que nosotros identificaríamos con el «principio de riesgo y ventura»):

«riesgos como los vinculados a una mala gestión o a errores de apreciación del operador económico no son determinantes a efectos de calificar un contrato como contrato público o como concesión de servicios, puesto que tales riesgos, en efecto, son inherentes a cualquier contrato, ya se trate de un contrato público de servicios o de una concesión de servicios».

En alguna sentencia posterior, vuelve a utilizarse, como en la sentencia Eurawasser, una concepción «relativa» (no «absoluta») del riesgo. No importa que el riesgo asociado a la gestión del servicio sea pequeño, mientras sea efectivamente transmitido al concesionario. Por ello, no hay concesión (sino contrato de servicios) si el contratista «no asume una parte significativa del riesgo que corre el poder adjudicador», de modo que no hay concesión cuando el contrato incluye cláusulas de protección ante pérdidas o insuficiencia de ingresos ${ }^{32}$. Nótese la indudable «rebaja» en las exigencias de asunción del riesgo: se pasa de exigir la

Curiosamente, se afirma que «no deben tenerse en cuenta los riesgos generales derivados de las modificaciones de la normativa acaecidas durante la ejecución del contrato» (párrafo 79). Es importante porque se trata precisamente de riesgos que en algunas concesiones no se transmiten al concesionario, al tratarse de factum principis. La conclusión es que el hecho de que el contratista reciba el pago de los usuarios y no de la entidad concedente no excluye que se trate de un contrato de servicios, salvo que «la otra parte contratante asuma la totalidad, o, al menos, una parte significativa, del riesgo de explotación que corre la entidad adjudicadora, incluso si dicho riesgo es, desde el inicio, muy limitado debido a la configuración jurídico pública de los servicios» (párrafo 80).

30 Sentencia Privater Rettungsdienst (10 de marzo de 2011, Sala 3. ${ }^{\text {, }}$ C-274/09, cuestión prejudicial de Munich, párrafos 37-38).

31 Ante las similitudes entre este caso y el de los conciertos de asistencia sanitaria (sentencia de 27 de octubre de 2005 , asunto C-158/03, Comisión contra España, párrafo 32) en el que el Tribunal falló que no se trataba de una concesión, cabe preguntarse si la diferencia respuesta tiene que ver con que en el asunto Privater Rettungsdienst se trataba de una fórmula de contratación que, aunque no encajaba en las normas de la Directiva de contratos sobre la licitación, podía ser considerada razonable en el ámbito de los servicios sociales (y de hecho habría sido «rescatada» por la Directiva 2014/18, que flexibiliza la contratación en este ámbito), mientras que en el asunto de los conciertos de asistencia sanitaria nos encontramos ante una contratación con empresas, pura y simple, sólo que tramitada (incorrectamente) como concesión y no en forma de contrato de servicios.

32 Sentencia de 10 de noviembre de 2011 (Sala 2. ${ }^{a}$, asunto C-348/10, Norma-A, cuestión prejudicial planteada desde Letonia, párrafos 44-49). 
asunción «del riesgo de explotación» (sentencias de 2005-2007) a exigir que suma «una parte significativa del riesgo» que inicialmente tenía el poder adjudicador (sentencias de 2009-2011), que además puede ser, de por sí, pequeño (por ejemplo en el caso Privater Rettungsdienst).

Enlazando con lo anterior, es importante subrayar que la naturaleza jurídica del contrato (es decir, si se trata de una concesión o no) depende de las obligaciones que asume el concesionario a lo largo de la vida del contrato pero también de puntuales obligaciones que puede asumir la Administración, que sólo operan en determinados momentos (que pueden no producirse), pero que limitan durante toda la vida del contrato el riesgo asumido por el concesionario.

Para sintetizar las conclusiones de este examen de la jurisprudencia, podemos comenzar recordando que al Tribunal no le preocupa la asunción de riesgos por los concesionarios o el peligro que para el interés público puede esconderse en cláusulas de protección del concesionario que obliguen a la Administración a costosos rescates. Lo único que le preocupa es que se utilice el procedimiento de licitación adecuado, es decir, que no se licite como concesión (lo que hasta hace poco significaba sin procedimiento regulado por el Derecho comunitario) algo que en realidad no es una concesión, sino un contrato de servicios. Las mismas cláusulas que no son admisibles en una concesión (porque suponen que el concesionario no asume el riesgo) son perfectamente válidas en un contrato de servicios.

También cabe observar una progresiva flexibilización del riesgo que debe asumir el concesionario, dirigida a «salvar» fórmulas de gestión a las que tienen apego determinados Estados (Alemania) y que se desarrollan en ámbitos (colaboración interadministrativa, servicios sociales) en los que el propio legislador comunitario reconoce la conveniencia de no obligar a los Estados a grandes cambios ${ }^{33}$. Se trata, además (sentencias Eurawassery Privater Rettungsdienst), de concesiones de servicios, en las que no hay una obra asociada con sus correspondientes gastos de inversión. En esa progresiva flexibilización, ya no se exige que el concesionario asuma el riesgo de explotación, sin más, sino «una parte significativa» del riesgo, lo que al final se resume en la posibilidad de sufrir pérdidas, siempre que vaya más allá del riesgo que asume todo empresario en un contrato.

Como veremos a continuación, lo interesante es que esta jurisprudencia del TJ, surgida sobre todo en el contexto de concesiones de servicios, va a encontrar reconocimiento general en la Directiva, al fusionarse con otra doctrina muy particular, la de las normas europeas de contabilidad, que curiosamente surge en un ámbito diferente (el de las concesiones de obra y los proyectos de colaboración público-privada), caracterizado justamente por el protagonismo de la obra construida y financiada por el empresario privado y cuyo coste debe recuperarse a través de los mecanismos de remuneración previstos en el contrato.

Es necesaria una última acotación. Quien lea la Exposición de Motivos de la Ley 13/2003 con sus llamadas al rigor en la asunción del riesgo por parte del concesionario, verá que al legislador no le preocupaba sólo el respeto de los procedimientos de licitación, porque en la legislación española éstos son sustancialmente iguales en las concesiones de obras y en los contratos de obras o de servicios. Lo que intenta decir esa Exposición de Motivos ( $\mathrm{y}$ lo dice con claridad, algo desmentida en su aplicación práctica) es que la concesión no supone para la Administración el riesgo económico de tener que rescatar al concesionario (como tantas veces había pasado con anterioridad), porque el riesgo lo asume el concesionario ${ }^{34}$. Palabras que resultaron desmentidas, desde luego, por la conocida «responsabilidad patrimonial administrativa» del artículo 266.1 de la LCAP (incorporado por la Ley 13/2003), que después pasó a la LCSP de 2007 y al artículo 271.1 del TRLCSP hasta su reforma por la Ley 40/2015. Pero la jurisprudencia del TJ ni siquiera ofrece ese consuelo (o promesa) de que la concesión supone la externalización del riesgo y su traslado al concesionario, porque, bajo el principio de que el concesionario debe asumir «una parte significativa del riesgo», es perfectamente posible que el poder adjudicador retenga una parte del riesgo que genere para él compromisos financieros importantes, bien desde el principio, bien si se producen determinadas circunstancias en la explotación de la concesión.

\section{b) El riesgo concesional en la normativa europea sobre contabilidad pública (SEC-2010)}

Si en la Directiva 2014/23 pueden reconocerse fórmulas y reglas procedentes directamente de la jurisprudencia del TJ, otras tienen su origen inmediato en las normas europeas de contabilidad pública, apro-

33 Párrafos 5 y 7 de la Directiva 2014/24 y párrafos 5-6 de la Directiva 2014/23.

34 Sobre esta cuestión, vid. A. RUIZ OJEDA, La concesión de obras públicas, Civitas, Cizur Menor, 2006, pág. 733, resumiendo su posición en unas palabras que se han revelado premonitorias: "¿cuántas veces apelaremos al sector privado para gestionar y financiar infraestructuras para que, al final, sea la Administración -en realidad las generaciones venideras- la que tenga que hacerse cargo de las ruinas?». 
badas en forma de Reglamento y conocidas en español, en su versión vigente, como SEC-2010 ${ }^{35}$. Esas normas deben ser cumplidas por los Estados miembros al elaborar sus cuentas públicas, y su cumplimiento es controlado por EUROSTAT, que ha aprobado un Manual que desarrolla estos criterios ${ }^{36}$.

Si el TJ intenta evitar que se liciten como concesiones contratos que en realidad lo son de obras o de servicios (pero no auténticas concesiones), lo que preocupa a EUROSTAT es la transparencia de las cuentas, es decir, que éstas reflejen los auténticos compromisos financieros asumidos por los Estados (en lugar de ocultarlos) y que las cifras de déficit y de deuda pública sean creíbles y se puedan establecer comparaciones adecuadas entre unos Estados y otros, y tenga sentido afirmar que un Estado "cumple» los objetivos marcados por la normativa europea de estabilidad presupuestaria ${ }^{37}$. A EUROSTAT no le preocupa en absoluto la adecuada licitación del contrato (que se da por supuesta), y tampoco le importa (y se dice expresamente) la mayor o menor eficiencia de estas fórmulas, sino la adecuada contabilización de los compromisos reales asumidos por los Estados ${ }^{38}$. Si el TJ intenta evitar la «huida a las concesiones» como vía para eludir el cumplimiento de las normas sobre licitación y adjudicación, a EUROSTAT le importa evitar la «huida al capital privado» con la que se intenta compensar la escasez de recursos públicos y eludir los límites normativos del déficit y la deuda públicos.

Las normas SEC-2010 no están pensando en cualquier tipo de concesiones, sino fundamentalmente en las concesiones de obra y en las concesiones de servicio que incluyen la ejecución de obras, puesto que es en ellas donde se realizan importantes inversiones (construcción de una autopista, un edificio público, etc.) cuya contabilización puede plantear problemas, puesto que no es lo mismo contabilizar todo el coste de la inversión en un año, lo que supone un fuerte incremento del déficit público y de la deuda, que contabilizarlo en forma de concesión o de proyecto de colaboración público-privado, lo que supone contabilizar únicamente en cada año el coste de los pagos que la Administración debe hacer al concesionario, con un impacto muy limitado sobre el déficit público. Pero estas reglas van a pasar a la Directiva y aplicarse a todas las concesiones, incluidas aquellas que no suponen la ejecución de obras o sólo en muy pequeña medida.

Las reglas SEC-2010, que tanto influyen en la regulación sustantiva de los contratos públicos, se basan en unas categorías que no se ajustan a las que utilizan las Directivas. Así, para estas normas, sólo hay «concesión» cuando el peaje por la utilización de la obra lo paga el usuario, no en el caso del «peaje en sombra» ${ }^{39}$. Por ello, las normas sobre riesgo operacional, riesgo de demanda y riesgo de suministro, que han pasado a la Directiva 2014/23, no proceden de la regulación que contienen las normas SEC-2010 sobre las concesiones, sino de la regulación de los proyectos de colaboración entre el sector público y el privado (PPP), que son el correlato financiero del antiguo contrato de colaboración público-privado.

Esto es importante, porque en los PPP en muchas ocasiones no existe riesgo de demanda, en la medida en que el único usuario potencial de la obra construida es la Administración o se trata de un uso obligatorio y predecible (pensemos en el supuesto de un contrato que sirve para la construcción de una prisión o de un hospital, a cargo del contratista y con pagos periódicos por parte de la Administración). En esos contratos no existe riesgo de demanda, y por ello se exige que el concesionario asuma otros riesgos (de construcción, de

${ }^{35}$ Reglamento (UE) núm. 549/2013 del Parlamento Europeo y del Consejo de 21 de mayo de 2013 relativo al Sistema Europeo de Cuentas Nacionales y Regionales de la Unión Europea. En la doctrina española, A. B. MACHO PÉREZ/E. MARCO PEÑAS, "EI impacto de las colaboraciones público-privadas en los niveles de déficit y deuda públicos: análisis de los criterios de Eurostat", RAP, 194 (2014), págs. 437-474.

${ }_{36}$ Manual on Government Deficit and Debt. Imprementation of ESA 2010, Eurostat, 2016.

37 Manual, cit., pág. 332 (párrafo 3), pág. 334 (párrafo 10), pág. 337 (párrafo 24). Por explicarlo con un ejemplo, se trata de esas reglas que Grecia incumplió constantemente en la década de los 2000 , provocando, cuando llegó la crisis financiera, el gravísimo problema que toda Europa ha vivido durante estos últimos años (hasta 2015 aproximadamente).

${ }_{38}$ «No corresponde a los estadísticos examinar las razones, el sentido o la eficiencia (análisis costes/beneficios) de estas formas de colaboración [público privada], o expresar una opinión sobre la viabilidad económica o financiera de los proyectos a los que las mismas se aplican, en especial en comparación con otras formas de realizar inversiones. El papel de los estadísticos se limita a fijar criterios claros para el tratamiento de los CPP en las cuentas públicas nacionales y, en el contexto del procedimiento de déficit excesivo, sobre su impacto en las cifras de déficit y deuda. Por tanto, es importante aplicar correctamente los principios de contabilidad pública para asegurar el respeto de las normas y la homogeneidad de las estadísticas oficiales en todos los Estados miembros, de modo que las cifras de déficit y deuda sean totalmente comparables entre ellos» (Manual, cit., págs. 334-335, párrafo 12).

Por poner un ejemplo, la forma más económica de obtener una obra pública puede ser un contrato de obra financiado con fondos obtenidos a través de una emisión de deuda pública (cuyo coste es inferior al de la financiación bancaria). Una concesión será normalmente más cara por múltiples razones, como la necesidad de cubrir el beneficio del concesionario, o el mayor coste de la financiación de la obra cuando es éste quien la solicita, además del coste que el concesionario exige para cubrir los riesgos que él asume. Pero este factor es irrelevante para las normas sobre contabilidad.

39 Manual, cit., pág. 324 (párrafo 16). 
disponibilidad). Pero el resultado es que, por influencia de las reglas SEC, en la Directiva (y en la LCSP) ya no se exige que el concesionario asuma el riesgo de demanda en ningún caso, ni siquiera en los contratos en los que sí existe ese riesgo ${ }^{40}$.

Las normas SEC no exigen que el «concesionario» (es decir, el empresario privado en general, también cuando el contrato no es calificado por las normas SEC como concesión, sino como PPP) asuma «el riesgo», es decir, «todo el riesgo», sino «la mayor parte del riesgo» ${ }^{41}$.

Esta exigencia se manifiesta en una regla fundamental: existe concesión (o PPP) y, por tanto, la inversión no cuenta para el déficit ni para la deuda pública, cuando el concesionario asume el riesgo de construcción y además el riesgo de demanda o el de disponibilidad. Veremos cómo la Directiva, al tener alcance general, no limitado a los contratos que prevén la construcción de obras, suprime la referencia al riesgo de construcción, exigiendo únicamente que el concesionario asuma el riesgo de demanda o el riesgo de suministro (cuya equivalencia con el riesgo de disponibilidad es discutible, aunque evidentemente hay un paralelo con el par de conceptos «riesgo de demanda/riesgo de disponibilidad» de las normas SEC) ${ }^{42}$.

Es fácil entender el concepto de riesgo de demanda ${ }^{43}$. El riesgo de disponibilidad consiste, por su parte, en que la retribución del concesionario dependa, al menos en parte, de la correcta prestación del servicio o de que la obra se encuentre en las condiciones fijadas en el contrato, de modo que su retribución se reduzca si la obra o servicio no se presta, o no alcanza los estándares de calidad y cantidad fijados en el contrato ${ }^{44}$. La falta de disponibilidad ha de afectar a la retribución, no sólo a la imposición de penalidades. El mayor problema jurídico estriba en distinguir este «riesgo de disponibilidad», que en las normas SEC-2010 es suficiente para que un contrato de colaboración público-privado (PPP) no compute como déficit y deuda públicos (siempre que el contratista asuma también el riesgo de construcción), del normal «riesgo y ventura» que afecta a todo empresario y que en la contratación pública está expresamente colocado a cargo del contratista.

40 A. ROMÁN MÁRQUEZ, en el trabajo ya citado «El riesgo en las concesiones", págs. 462-463, viene a decir que si la obra o servicio concedidos no tienen usuarios que puedan optar por utilizarlos o no hacerlo, sino que se trata de una obra o servicio utilizada por la Administración, no puede haber riesgo concesional ni concesión. El contrato de colaboración público-privado no sería una concesión. Textualmente: "puede identificarse a los usuarios como el tercer elemento de la relación concesional, junto a la autoridad concedente y al concesionario privado. Precisamente sería la ausencia de usuarios, entendiéndose como tales los ciudadanos que voluntariamente demandan una obra o servicio público, la que permite negar la naturaleza concesional a aquéllas infraestructuras construidas por el sector privado para el uso exclusivo de la Administración contratante (v.gr. edificio destinado a sede administrativa, prisión o instalación militar), y sobre las que la propia Directiva 2014/23 guarda silencio. (...) En definitiva, el riesgo concesional proviene de la explotabilidad de la obra o servicio, y sin usuarios particulares no existe ni lo uno ni lo otro». En nota aclara que se está refiriendo a los contratos de colaboración público privada, que -aclara este autor- en Italia sí están comprendidos en el concepto legal de concesión de obras.

Verdaderamente A. ROMÁN MÁRQUEZ pone el dedo en la llaga de un problema real, como son las innegables diferencias entre una concesión con riesgo de demanda y un contrato en el que una parte construye y mantiene un objeto que va a ser utilizado por la Administración. Si queremos construir este segundo contrato de una forma que no compute como déficit ni como deuda, es necesario (SEC-2010) que el contratista asuma determinados riesgos, para lo que SEC-2010 construye el concepto de «riesgo de disponibilidad». Sin embargo, la doctrina parece de acuerdo en que la supresión en la LCSP de 2017 del antiguo «contrato de colaboración públicoprivada» supone su reconducción a las concesiones: «En todo caso, la opción de realizar CPP (desde la perspectiva de SEC 2010) se encuentra en la regulación de concesiones» [J. M. GIMENO FELIU, "Hacia una nueva Ley de Contratos del Sector Público. ¿Una nueva oportunidad perdida?", REDA, 182 (2017), págs. 181-221, pág. 206]. Sobre la distinción entre CPP y concesiones cuando existía una regulación expresa para los CPP, vid. M. HERNANDO RYDINGS, La colaboración público privada. Fórmulas contractuales, Civitas, Cizur Menor, 2012, págs. 409-421.

41 Manual, cit., pág. 325 (párrafo 25), pág. 332 (párrafo 4).

42 Niega esa equivalencia A. ROMÁN MÁRQUEZ, op. cit. pág. 464, para quien el riesgo de disponibilidad de SEC-2010 no equivale al «riesgo de oferta» de la Directiva 2014/23: «puede concluirse, sin género de dudas, que la Directiva 2014/23 no admite el riesgo de disponibilidad como un riesgo propio de las concesiones, y no lo hace porque está relacionado con el riesgo interno de la concesión, vinculado a la gestión empresarial de la misma, y que para el legislador comunitario no constituye un riesgo característico de las concesiones al ser común a cualquier relación contractual». Sobre esta cuestión volveré infra, al estudiar el texto de la Directiva, aunque entiendo que: [1] A. ROMÁN MÁRQUEZ tiene razón al subrayar que el riesgo de disponibilidad es muy limitado y no se corresponde con el riesgo concesional en el sentido tradicional, pero [2] la expresión «riesgo de oferta» en la Directiva tiene mucho que ver con el riesgo de disponibilidad ( $y$ así lo ha interpretado el legislador español al prever los «pagos por disponibilidad», como veremos).

${ }^{43}$ Es el riesgo cuyo cálculo erróneo provoca la ruina de las concesiones que fracasan, como algunas de las autopistas de peaje adjudicadas al amparo de la Ley 13/2003 o aparcamientos subterráneos en régimen de concesión.

${ }^{44} \mathrm{El}$ riesgo de disponibilidad (availability risk) se define en el Manual, cit., págs. 333 (párrafo 5) y 340 (párrafo 40). Se refiere «al volumen y calidad de la prestación (ligados a la actuación del contratista)». «El riesgo de disponibilidad se refiere a casos en los que, durante la fase de explotación del activo [la obra], el contratista incurre en responsabilidad debido a su defectuosa gestión, que da como resultado que el volumen de servicios prestados esté por debajo de lo acordado en el contrato, o que los servicios no alcancen los niveles de calidad especificados en el contrato». 
No hay que olvidar que en las normas SEC existe un sesgo favorable a admitir la colaboración públicoprivada, que es una técnica que las instituciones de la UE consideran irrenunciable para la realización de inversiones públicas y que constituye el instrumento principal del denominado «Plan Juncker» ${ }^{45}$.

Para la calificación del contrato no se tienen en cuenta únicamente las obligaciones principales asumidas por las partes, en cuyo cumplimiento consiste la ejecución del contrato, sino también otras que están previstas de forma condicional, es decir, que sólo entrarán en juego si se producen determinadas circunstancias. Destacan especialmente en este sentido las cláusulas que otorgan garantías específicas al concesionario, limitando el riesgo que asume. Es el caso de la mal llamada (pero expresivamente llamada, y de ahí que el concepto haya hecho fortuna) «responsabilidad patrimonial administrativa», es decir, la norma que establece que en caso de resolución del contrato por cualquier causa -no sólo por causas imputables a la Administración concedente-, ésta abonará al concesionario el importe de la inversión realizada, salvo la parte que ya se haya amortizado ${ }^{46}$. Esta regla, que se incorporó a la Ley 13/2003 procedente de la Ley de autopistas de peaje de $1972^{47}$, llevó a que numerosos contratos de concesión de obra, que inicialmente se habían clasificado, a efectos de contabilidad pública, como concesiones de obra o PPP (en todo caso, sin que el importe total de la inversión fuera computado como déficit ni deuda pública ${ }^{48}$, fueran reclasificados, originando «picos» de déficit importantes en algunas Administraciones Públicas ${ }^{49}$. De hecho, la modificación de la «responsabilidad patrimonial administrativa» en la Ley 40/2015, que forma parte de un paquete de reformas de la legislación de contratos que no se quiso hacer esperar hasta la aprobación de la nueva LCSP, probablemente no tenía como intención principal la de evitar que las Administraciones tuvieran que asumir nuevos rescates en futuras concesiones de obra (impedir, por tanto, la repetición del episodio de las radiales), sino la de facilitar la utilización en el futuro de la concesión de obra, puesto que, si no se hubiese realizado esta modificación, esta clase de proyectos y concesiones se habrían contabilizado del mismo modo que los contratos de obra, computando el total de la inversión en la cifra de déficit y de deuda pública, privándolos así de uno de sus principales atractivos para las Administraciones Públicas.

Otra de esas cláusulas que plantean problemas desde el punto de vista de las reglas SEC es la que determina que las tarifas y otros parámetros de la concesión (como el plazo) se modifiquen cuando los ingresos por peajes queden por debajo o por encima de unos umbrales marcados en el PCAP. Tanto la Ley 13/2003 (incorporada al TRLCSP) como la nueva LCSP de 2017 establecen que los pliegos de los contratos de concesión de obra incorporen esta clase de cláusulas, que tienden a proteger al concesionario frente a situaciones de ingresos muy inferiores a los esperados, y a la vez a poner un tope a sus beneficios en caso de que la utilización de la obra supere las expectativas ${ }^{50}$. Estas cláusulas aparente-

45 Sobre esta cuestión, es útil mencionar las Conclusiones del Consejo de Asuntos Económicos y Financieros sobre la resolución de los obstáculos a la inversión identificados con arreglo al tercer pilar del Plan de Inversiones (6 de diciembre de 2016): «El uso de las asociaciones público-privadas (APP): Las asociaciones público-privadas pueden, si se utilizan de un modo adecuado, hacer de facilitadores para tipos específicos de inversiones y ofrecer una vía alternativa para la prestación de bienes y servicios públicos. Al tratarse de obligaciones contractuales a largo plazo requieren sin embargo un compromiso fuerte y estable de los socios de los sectores público y privado y constituyen, en potencia, una fuente de riesgo para las finanzas públicas. Su uso es a menudo dificultado por condiciones marco desfavorables como la falta de recursos administrativos, la inestabilidad e ineficiencia del marco regulador y una falta de compromiso político con inversiones a largo plazo. En determinadas circunstancias, los fondos de la UE pueden contribuir a la financiación de las APP y los recientes cambios en el Reglamento deben facilitar la combinación de los fondos de la UE y las APP».

${ }_{46}$ El dictamen de 23 de julio de 2014 (referencia 9/2014) habla de la «mal llamada responsabilidad patrimonial de la Administración -esto es, el valor patrimonial de la inversión realizada por la concesionaria- que tiene que abonar la Administración, entre otros casos, en los de resolución del contrato de concesión».

${ }_{47} \mathrm{Me}$ he referido a estos antecedentes en el trabajo «Un contrato administrativo, ¿puede ser resuelto por un Juzgado de lo Mercantil? (En torno a las sentencias de 5 y 15 de diciembre del Tribunal de Conflictos de Jurisdicción, recaídas en los conflictos de jurisdicción números 5 y 6 de 2016)», Anuario de Derecho Concursal, 41 (2017), págs. 85-97.

${ }^{48}$ Manual, cit., pág. 347 (párrafo 72). «Si la insolvencia del empresario se produce durante la fase de explotación, el contrato debería prever expresamente que, si se le tiene que abonar alguna compensación cuando el Gobierno reciba la obra, dicha compensación no excederá el valor de mercado que tenga la obra en ese momento (minorado en el coste que se estime que requerirá poner el activo en condiciones adecuadas para su explotación), resultante de un nuevo proceso de licitación o calculado por expertos independientes».

49 Aunque la decisión definitiva sobre la aplicación de las reglas SEC corresponde a EUROSTAT, dentro de cada Estado miembro existe una instancia encargada de aplicarlas a las distintas entidades públicas afectadas por ellas. En España, la IGAE es el órgano competente para revisar la adecuada contabilización de los gastos por las Comunidades Autónomas y las entidades locales. Las decisiones de reclasificación (como la que afectó a distintas concesiones de obra) se adoptan en un procedimiento informal con audiencia de los entes afectados, que pueden optar por que el asunto se lleve a decisión de Eurostat, cuyas decisiones sobre la clasificación de distintas concesiones y proyectos de colaboración entre el sector público y el sector privado (que aplican las reglas sobre asunción del riesgo), se publican en su página web.

50 Artículo 250.1.d), apartado $4 .^{\circ}$, de la LCSP: «Deberá ser objeto de consideración específica [en el PEF, integrante del PCAP] la incidencia en las tarifas, así como en las previsiones de amortización, en el plazo concesional y en otras variables de la concesión 
mente son sensatas en el sentido de que distinguen entre el riesgo "ordinario», asumido por el concesionario, y el riesgo ante situaciones imprevistas (y teóricamente imprevisibles), que sería compartido por la Administración. A la vez, se evitarían situaciones de beneficios extraordinarios del concesionario, que vayan mucho más allá de la recuperación de costes y de la obtención de un beneficio «razonable». Pues bien, esta cláusula supone que la Administración pasa a compartir riesgos con el concesionario y se menciona expresamente en el Manual de Eurostat como cláusula que puede significar que el contratista no asume la mayor parte del riesgo y que la inversión debe ser computada íntegramente, elevando las cifras de déficit y deuda ${ }^{51}$.

El resultado, ciertamente sorprendente, es que se considera que el concesionario asume la mayoría del riesgo aunque no asuma el riesgo de demanda, porque es suficiente que asuma los riesgos de construcción y de disponibilidad. En cambio, una concesión en la que asume el riesgo de demanda pero con esa cláusula que limita dichos riesgos tanto por exceso como por defecto, puede no ser aceptada, de modo que la Administración concedente debe computar íntegramente la inversión en sus cuentas, lo que seguramente privará de interés (para ella) la operación. En definitiva, si la asunción de riesgo es muy elevada, la operación no será interesante para las empresas; si la asunción de riesgo es muy pequeña, la operación no será interesante para la Administración porque computará como déficit y deuda.

Las reglas SEC-2010 se aplican retroactivamente, en el sentido de que cada año deben ser tenidas en cuenta en la elaboración de las cuentas públicas, y deben ser aplicadas a la operaciones en marcha, sea cual sea el régimen aplicable (o la interpretación del mismo) cuando se adjudicó la concesión. Por ello, concesiones que fueron adjudicadas al amparo de la Ley 13/2003, y que en el momento de su adjudicación fueron clasificadas contablemente como concesiones (de modo que la Administración sólo computaba en sus cuentas los pagos anuales, no el importe completo de la obra), han sido «reclasificadas» después, con el consiguiente incremento del déficit público. Un incremento que evidentemente es sólo formal, porque no implica mayores pagos a cargo de la Administración, pero que puede ser relevante al suponer el incumplimiento de las normas de estabilidad presupuestaria y la limitación de otras inversiones.

En una valoración global, puede decirse que las reglas SEC-2010 no exigen que el concesionario asuma todos los riesgos, sino sólo la mayor parte ${ }^{52}$. También debe recordarse que no están pensando en las concesiones típicas, en las que son los usuarios los que remuneran al concesionario a través de peajes, sino más bien en proyectos en colaboración entre el sector público y el sector privado, en los que, o bien la obra es utilizada por la Administración (construcción de cárceles, hospitales, etc.) o bien se aplica el peaje en sombra. A diferencia de lo que sucedía con las concesiones típicas, que en principio son gratuitas para la Administración salvo que entre en juego alguna cláusula que le obligue a asumir pérdidas (como la «responsabilidad patrimonial administrativa»), en este caso estamos hablando de contratos que siempre van a tener un coste para la Administración, y lo que está en juego es el alcance y la previsibilidad de ese coste. Esta consideración debe tenerse en cuenta, en mi opinión, a la hora de regular el procedimiento de preparación del contrato, puesto que cuando se toma la decisión de aprobar un proyecto de obra, es necesario tener muy claro si el proyecto puede generar costes para la Administración o no. En este segundo caso (que es el que la Ley 13/2003 daba por supuesto, aunque después la realidad ha sido muy distinta como consecuencia de la entrada en juego de la «responsabilidad patrimonial administrativa») las cautelas son mucho menores y el procedimiento reviste una naturaleza casi autorizatoria de una iniciativa económica cuyos riesgos son asumidos por el sector privado.

\section{LA REGULACIÓN DEL RIESGO OPERACIONAL EN LA DIRECTIVA 2014/23}

La aprobación de la Directiva 2014/23/UE supone que el Derecho comunitario pasa a regular por primera vez el procedimiento de licitación y adjudicación de las concesiones, que hasta ese momento en las concesiones de servicios carecía de regulación en las Directivas y sólo estaba sujeto a los criterios (más

previstas en el pliego, en su caso, de los rendimientos de la demanda de utilización de las obras y, cuando exista, de los beneficios derivados de la explotación de la zona comercial, cuando no alcancen o cuando superen los niveles mínimo y máximo, respectivamente, que se consideren en la oferta». En el mismo sentido, el artículo 131.1.c), apartado 4. ${ }^{\circ}$, del TRLCSP.

51 Manual, cit., pág. 342 (párrafo 52). El Manual está pensando en cláusulas en cuya virtud la parte pública (la Administración concedente) percibe una parte del beneficio cuando éste supera un determinado nivel.

52 Manual, cit., pág. 339 (párrafo 35). 
amplios) del Derecho originario (los Tratados) y en las concesiones de obras tenía unos criterios mucho más laxos que en los demás contratos. De todas formas, las normas de esta Directiva son menos exigentes que las de la Directiva 2014/24 (de contratos), de donde se deriva que sigue siendo necesario interpretar estrictamente el concepto de concesión para evitar que los poderes adjudicadores lo utilicen como una vía de escape de los procedimientos de adjudicación de los contratos. Prueba de ello es la regulación de los contratos mixtos en la Directiva 2014/24 (artículo 3), según la cual, si un contrato mixto reúne prestaciones sometidas a la Directiva 2014/24 y otras sometidas a la Directiva 2014/23, y son objetivamente separables, se aplicará la Directiva 2014/24 a todo el contrato, aunque su objeto principal esté formado por prestaciones sometidas a la Directiva 2014/23.

En esta Directiva la asunción del riesgo sigue siendo un elemento imprescindible del concepto de concesión (como no puede ser de otro modo), si bien ahora se incorpora expresamente a la definición legal, mientras que con anterioridad tenía que ser deducido a partir de una definición legal que sólo se fijaba en la forma de remuneración del concesionario, consistente total o parcialmente en el derecho temporal a explotar la obra o el servicio concedidos. A esta definición del riesgo también se incorporan elementos procedentes de la jurisprudencia y de las normas SEC-2010, como veremos a continuación.

El artículo 5.1 recoge la definición de las concesiones de las Directivas anteriores (que exige, como ya sabemos, que se otorgue al concesionario al derecho temporal a la explotación de la obra o servicio concedidos), pero añadiendo la referencia al riesgo:

«La adjudicación de las concesiones de obras o servicios implicará la transferencia al concesionario de un riesgo operacional en la explotación de dichas obras o servicios abarcando el riesgo de demanda o el de suministro, o ambos».

Nótese que, como he venido anticipando, no se exige la transferencia o la asunción del riesgo operacional, sino de un riesgo operacional, lo que quiere decir -y así se reconoce expresamente- que la transferencia puede ser parcial, por lo que la Administración podrá retener riesgos, lo que ratifica que la concesión no es inocua o gratuita para la Administración, porque no supone una transferencia total del riesgo. De hecho, ni siquiera se exige que el concesionario asuma el «riesgo operacional sustancial», como decía la propuesta de Directiva.

La posible retención de una parte del riesgo por la Administración se reconoce expresamente en el preámbulo (párrafo 18), que admite que la transferencia de riesgo es válida aunque «parte del riesgo siga asumiéndolo el poder o entidad adjudicador». La doctrina alemana, siempre al quite para «salvar» bajo el cómodo ropaje de la Directiva de concesiones el mayor número posible de fórmulas de gestión de los servicios públicos, insiste en que basta una transferencia «mínima» de riesgos para que el contrato pueda ser calificado y licitado como concesión ${ }^{53}$. El único límite impuesto por la Directiva es que la transferencia de riesgos no sea insignificante ${ }^{54}$.

Por otro lado, en una cita muy evidente de la sentencia Eurawasser (también dirigida a «salvar» concesiones en ámbitos de muy escaso riesgo), se añade que «[e]l hecho de que el riesgo esté limitado desde el principio no impedirá que el contrato se considere una concesión» (párrafo 19).

Ese riesgo mayor o menor cuya transferencia sigue siendo necesaria, puede consistir (aquí el origen son las reglas SEC-2010) en el riesgo de demanda o el de oferta. El riesgo de demanda es «el que se debe a la demanda real de las obras o servicios objeto del contrato» (párrafo 20 del preámbulo), mientras que el de oferta (que parece un trasunto del «riesgo de disponibilidad» de SEC-2010, aunque ciertamente no se ha

53 Vid. M. OPITZ, "Die Zukunft”, cit., pág. 756. El autor dice que la Directiva puede obligar a reconsiderar el criterio seguido por alguna jurisprudencia civil alemana (la encargada de resolver los litigios en materia de adjudicación de contratos, como sabemos), que exigía que el concesionario asumiera como mínimo el $50 \%$ del riesgo. Para M. KNAUFF/E. BADENHAUSEN, "Die neue Richtlinie über die Konzessionsvergabe”, NZBau, 2014, págs. 395 y sigs., «la nueva regulación sigue la jurisprudencia del TJUE, pero se queda atrás, en la medida en que falta un pronunciamiento sobre hasta qué punto y en qué ámbito se debe asumir el riesgo operacional». R. STEIN, "Mehr Regeln (und Ausnahmen): Die neue Konzessionsvergaberichtlinie”, en PÜNDER/PRIEB (Hrsg.), Vergaberecht im Umbruch II. Die neuen EU-VergaberichtInien und ihre Umsetzung, Hamburg, 2015, págs. 101-126, dice que «no existe ninguna indicación de que el concesionario debe asumir una parte "esencial" o "predominante" del riesgo. El riesgo asumido debe ser sustancial, pero no necesariamente superior a la parte del riesgo que asume la parte concedente» (pág. 110). En el mismo sentido, B. RUHLAND en GABRIEL/ KROHN/NEUN (Hrsg.), Handbuch des Vergaberechts, Beck, München, 2014 (págs. 130-131).

54 «La parte de los riesgos transferidos al concesionario supondrá una exposición real a las incertidumbres del mercado que implique que cualquier pérdida potencial estimada en que incurra el concesionario no es meramente nominal o desdeñable». Se trata de una traducción gramaticalmente desafortunada. Lo que quiere decir el preámbulo es que se exige que la transferencia de riesgos «implique que el concesionario puede incurrir en una pérdida que no sea meramente nominal o desdeñable». 
querido utilizar esa palabra) es «el relativo al suministro de las obras o servicios objeto del contrato, en particular el riesgo de que la prestación de los servicios no se ajuste a la demanda» (párrafo 20 del preámbulo) ${ }^{55}$. Esta posible identificación entre el «riesgo de suministro» de la Directiva y el «riesgo de disponibilidad» de las reglas SEC-2010 es una de las cuestiones abiertas a la discusión. Es significativo que en el procedimiento de elaboración de la Directiva no sólo se «cayera» la exigencia de que el concesionario asumiera una parte «sustancial» del riesgo, sino que se sustituyera «riesgo de disponibilidad» por «riesgo de suministro» ${ }^{56}$.

Digamos que, si aceptáramos «riesgo de disponibilidad» como equivalente a «riesgo de suministro» $\mathrm{y}$, por tanto, como una forma de asunción de riesgos suficiente para que el contrato sea una auténtica concesión, estaríamos al límite del concepto de concesión. ¿Por qué? Porque si alguna diferencia ha de existir entre el contrato de concesión y los contratos de obra o servicio, ésta consiste en que al concesionario, a diferencia de lo que sucede con los contratistas de obras o de servicios, no le basta, para cobrar, con ejecutar bien su prestación. El cobro de la prestación requiere algo más, que no depende de su voluntad sino de hechos ajenos a la misma. El ejemplo más claro es el riesgo de demanda: no basta construir y gestionar bien la autopista, hace falta que los usuarios quieran circular por ella. En cambio, el «riesgo de disponibilidad» supone que basta tener la autopista en condiciones de ser usada (con las características fijadas en el contrato). Parecería que, en el riesgo de disponibilidad, el único riesgo que asume el concesionario es el de que el contrato no sea rentable porque no le permita cubrir costes, pero ese riesgo lo asume cualquier contratista, público o privado (en el contrato de obra, pero también en el de servicios, por ejemplo). La única forma de entender el riesgo de suministro como una forma de riesgo operacional (es decir, concesional) consiste en interpretarlo en el sentido de que el concesionario asume el riesgo de que, como consecuencia de un posible exceso de demanda, se agote el servicio o las posibilidades de uso de la obra concedida, de forma que, aunque él esté cumpliendo correctamente la prestación, se produzca una denegación de uso o no se cumplan los estándares de calidad. Por ejemplo, el concesionario asumiría el riesgo de que se produjeran embotellamientos en la autopista concedida, y en ese caso dejaría de cobrar la remuneración.

Por otro lado, no se exige (a diferencia de SEC-2010) que el concesionario asuma el riesgo de construcción además del riesgo de demanda o el de suministro/disponibilidad. Es suficiente uno de estos dos últimos. La explicación es sencilla: la Directiva no está pensando sólo en concesiones de obras o de servicios que impliquen la construcción de una obra. También se incluyen concesiones sin obra (ya se trate de concesiones de servicios o incluso de concesiones de obras para la gestión de obras ya construidas, como serán, por ejemplo, las que se adjudiquen próximamente para la gestión de las autopistas radiales que la Administración ha tenido que asumir en virtud de la «responsabilidad patrimonial administrativa»).

Una vez que ha quedado claro que no es necesario que el concesionario asuma el riesgo de construcción (que puede no existir en determinadas concesiones) ni el riesgo de demanda -que era, sin embargo, el elemento más característico del antes denominado «riesgo de explotación de la obra»-y que tampoco hace falta (como exigía parte de la jurisprudencia) que el concesionario asuma todo el riesgo, mucho o poco, que exista en la obra o servicio objeto de concesión, el único criterio que queda es la exigencia de que el concesionario corra algún riesgo económico, es decir, la posibilidad de que el negocio resulte ruinoso o genere pérdidas:

- «Se considerará que el concesionario asume un riesgo operacional cuando no esté garantizado que, en condiciones normales de funcionamiento, vaya a recuperar las inversiones realizadas ni a

55 Como estamos viendo, el preámbulo de la Directiva tiene una importancia decisiva, que va más allá del valor puramente interpretativo, porque hay elementos decisivos para entender el contenido real de la norma que sólo están presentes en él, no en la parte dispositiva.

56 La propuesta de Directiva (artículo 2.2) decía que la concesión «implica la transferencia al concesionario del riesgo operacional sustancial. Se considerará que el concesionario asume el riesgo operacional sustancial cuando no esté garantizado que vaya a recuperar las inversiones realizadas ni a cubrir los costes que haya contraído para explotar las obras o los servicios que sean objeto de la concesión». El primer riesgo posible es el de demanda, y el otro es el «riesgo relacionado con la disponibilidad de las infraestructuras proporcionadas por el concesionario o utilizadas para la prestación de servicios a los usuarios».

El Comité competente del Parlamento Europeo aprobó (1 de febrero de 2013) una enmienda que dice que «la adjudicación de la concesión de obras o de servicios implicará la transferencia al concesionario de la parte sustancial del riesgo económico que conlleva la explotación de tales obras o servicios, definido como el riesgo de exposición a las incertidumbres del mercado, y que incluye tanto el riesgo de demanda como el de suministro».

El texto finalmente aprobado por acuerdo entre el Parlamento y el Consejo dice que la concesión «implicará la transferencia al concesionario de un riesgo operacional [ya no es "el riesgo operacional sustancial" ni "la parte sustancial del riesgo económico"] en la explotación de dichas obras o servicios abarcando el riesgo de demanda o el de suministro, o ambos [ya no se habla de disponibilidad, y queda claro que es suficiente uno de los dos riesgos]». 
cubrir los costes que haya contraído para explotar las obras o los servicios que sean objeto de la concesión» (art. 5).

- «la posibilidad de que no recupere las inversiones realizadas ni cubra los costes que haya sufragado para explotar las obras o los servicios adjudicados» (Preámbulo, párrafo 18).

- A sensu contrario, no nos encontramos ante una verdadera concesión «si el poder adjudicador o la entidad adjudicadora aliviase al operador económico de cualquier posible pérdida garantizando unos ingresos mínimos que sean iguales o superiores a las inversiones y los costes que el operador económico deba asumir en relación con la ejecución del contrato» (párrafo 18).

La referencia a las "condiciones normales de funcionamiento» (artículo 5) ha sido interpretada (WILLENBRUCH, cit. en nota 18, pág. 113) en el sentido de que basta que el concesionario asuma el riesgo en condiciones normales de mercado, de modo que el apoyo de la Administración concedente en circunstancias excepcionales no obstaría a la calificación del contrato como concesión. Una idea muy interesante, porque permite incorporar cláusulas de apoyo de la Administración al concesionario en circunstancias excepcionales similares a las que podemos encontrar en los artículos 127 y 129 del RSCL.

La pregunta que surge a continuación es fácilmente imaginable: ¿no se encuentran todos los contratistas (todos los empresarios), y no sólo los concesionarios, en esa misma situación? ¿Existe algún contratista que tenga "garantizado que, en condiciones normales de funcionamiento, vaya a recuperar las inversiones realizadas ni a cubrir los costes que haya contraído?» Creo que no. A fuerza de rebajar el «riesgo operacional» (rectius, la parte del riesgo operacional que tiene que asumir el empresario privado para que el contrato pueda calificarse como concesión), ese concepto ha "adelgazado» tanto que casi se ha quedado en el puro hueso del principio de riesgo y ventura, predicable de todos y cada uno de los contratos. Para salir al paso de esa reducción al absurdo, la Directiva retoma en su preámbulo (párrafo 20) las siguientes palabras, ya conocidas para el lector de este artículo, de la sentencia Privater Rettungsdienst:

«Un riesgo operacional debe derivarse de factores que escapan al control de las partes.

Los riesgos vinculados, por ejemplo, a la mala gestión, a los incumplimientos de contrato por parte del operador económico o a situaciones de fuerza mayor, no son determinantes a efectos de la clasificación como concesión, ya que tales riesgos son inherentes a cualquier tipo de contrato, tanto si es un contrato público como si es una concesión.

Un riesgo de operacional debe entenderse como el riesgo de exposición a las incertidumbres del mercado, que pueden consistir en un riesgo de demanda o en un riesgo de suministro, o bien en un riesgo de demanda y suministro» (párrafo 20). ${ }^{57}$

Por tanto, la Directiva de concesiones incorpora la jurisprudencia del TJ pero pasada por el tamiz de las reglas SEC-2010 y con una considerable rebaja. Estamos muy lejos de la idea de que el concesionario tenga que asumir «el riesgo de explotación» de la obra o servicio concedidos, como exigía la primera jurisprudencia $(2005,2007)$ y la Comunicación interpretativa de la Comisión del año 2000.

Además, el juego conjunto de normas pensadas para tipos concretos de concesiones trae como resultado una regulación válida para todas las concesiones que suma las limitaciones de riesgos surgidas de todas las experiencias sectoriales: (1) se elimina el riesgo de construcción porque en muchas concesiones de servicios y algunas de obras no existe, (2) se elimina el riesgo de demanda (que puede ser sustituido por el disponibilidad) porque en muchos proyectos de colaboración público-privado (que es donde que surgen las reglas SEC-2010) ese riesgo no tiene sentido, (3) se admiten concesiones con un riesgo muy pequeño para salvar algunas concesiones de servicios en sectores sujetos a una fuerte regulación que reduce el riesgo (casos Eurawasser o Privater Rettungsdienst). El resultado: concesiones de obra en las que sí hay obra pero en las que el concesionario no tiene que asumir ni el riesgo de construcción ni el de demanda.

Queda claro, en todo caso, que estos contratos de concesión en ningún caso son negocios libres de riesgo para los poderes adjudicadores concedentes, porque la asunción del riesgo por el concesionario puede ser limitada.

57 Nótese nuevamente cómo chirrían algunos conceptos. La Directiva, en el párrafo citado, dice que el riesgo de sufrir pérdidas como consecuencia de situaciones de fuerza mayor no es suficiente para calificar el contrato como concesión, «ya que tales riesgos son inherentes a cualquier tipo de contrato»... ¡ isalvo al contrato de obras del Derecho español, en que tales riesgos son asumidos por la Administración (artículo 239 LCSP)! 


\section{EL RIESGO OPERACIONAL EN LA NUEVA LCSP DE 2017}

Veamos ahora cómo ha incorporado la nueva LCSP el concepto de riesgo operacional.

Recordemos, de entrada, que en España la distinción entre concesiones (de obras y de servicios) y contratos (de obras y de servicios, respectivamente) no tenía relevancia para el procedimiento de licitación, porque, a diferencia de lo que pasaba en Alemania, las concesiones se adjudicaban a través de procedimientos igual de respetuosos con los principios de publicidad y concurrencia que los contratos de obras y servicios. Ni antes de la aprobación de la Directiva 2014/23 (cuando la adjudicación de las concesiones era libre en las de servicios, y no muy rigurosa en las de obras) ni tras su entrada en vigor (que fija un procedimiento, aunque mucho menos exigente que el de licitación de los demás contratos públicos) se ha aprovechado por el legislador español el amplio margen de que disponen los Estados miembros en la regulación de los procedimientos de licitación de las concesiones.

También hemos visto que la verdadera diferencia de régimen jurídico entre las concesiones y los tipos contractuales que se habrían aplicado en su defecto (fundamentalmente, el contrato de servicios en relación con la concesión de servicios) se refería al plazo, mucho más largo en las primeras. Esta diferencia desaparece, en la práctica, con la nueva LCSP. El plazo de las concesiones (regulado en el artículo 29.6) ya no puede fijarse sin más en el máximo (40 años para las concesiones de obras y las de servicios que impliquen ejecución de obras, 25 años para las de servicios que no impliquen ejecución de obras y 10 para las de servicios sanitarios que no impliquen ejecución de obras). Esos plazos máximos (que hasta ahora eran los únicos que había) son eso, un límite que no se puede superar, pero el plazo concreto, si se quiere que supere los cinco años, tendrá que ser «el que se calcule razonable para que el concesionario recupere las inversiones realizadas para la explotación de las obras o servicios, junto con un rendimiento sobre el capital invertido, teniendo en cuenta las inversiones necesarias para alcanzar los objetivos contractuales específicos ${ }^{58}$. Por otro lado, los contratos de servicios (artículo 29.4) ya no están sometidos a un rígido corsé, porque el plazo máximo (que ahora es de cinco años, incluidas prórrogas, ligeramente inferior al fijado en el artículo 303 TRLCSP, que era de 6 años, prórrogas incluidas), puede ser superior a ese máximo teórico en la medida en que «[e]xcepcionalmente, en los contratos de servicios se podrá establecer un plazo de duración superior al establecido en el párrafo anterior, cuando lo exija el período de recuperación de las inversiones directamente relacionadas con el contrato y éstas no sean susceptibles de utilizarse en el resto de la actividad productiva del contratista o su utilización fuera antieconómica, siempre que la amortización de dichas inversiones sea un coste relevante en la prestación del servicio, circunstancias que deberán ser justificadas en el expediente de contratación con indicación de las inversiones a las que se refiera y de su período de recuperación». Podría decirse que esa ampliación del plazo es una especie de «pista de aterrizaje» dirigida a facilitar el encaje en el contrato de servicios de aquellos contratos que se hayan concebido como concesiones (con sus plazos largos) pero no cumplan el requisito de la transferencia del riesgo.

Por tanto, el plazo ya no es una razón relevante para optar por la concesión frente al contrato de servicios. Sí lo es la búsqueda de un mejor tratamiento en la contabilidad pública, es decir, la pretensión de que la inversión no compute como déficit ni como deuda pública, aunque eso no va necesariamente ligado a la calificación del contrato, al tratarse de normas diferentes (aunque de contenido similar) que van a aplicar distintos órganos.

En todo caso, la nueva definición legal de las concesiones recoge el concepto de riesgo operacional en los mismos términos que la Directiva, como no puede ser de otro modo. El artículo 14.4 dice que la concesión «deberá implicar la transferencia al concesionario de un riesgo operacional en la explotación de dichas obras [o de dichos servicios] abarcando el riesgo de demanda o el de suministro, o ambos». A continuación se incorporan textualmente las determinaciones de la Directiva sobre el riesgo operacional y sus clases $^{59}$.

58 Con un punto de cinismo, imprescindible en esta materia, cabe decir que la Administración siempre puede «estirar» el plazo concesional hasta acercarse al máximo, imponiendo el pago de un elevado canon concesional para cuya amortización sea necesario un periodo de explotación prolongado.

59 «Se entiende por riesgo de demanda el que se debe a la demanda real de las obras o servicios objeto del contrato y riesgo de suministro el relativo al suministro de las obras o servicios objeto del contrato, en particular el riesgo de que la prestación de los servicios no se ajuste a la demanda.

Se considerará que el concesionario asume un riesgo operacional cuando no esté garantizado que, en condiciones normales de funcionamiento, el mismo vaya a recuperar las inversiones realizadas ni a cubrir los costes en que hubiera incurrido como consecuencia de la explotación de las obras que sean objeto de la concesión. La parte de los riesgos transferidos al concesionario debe suponer una 
Curiosamente, en múltiples preceptos de la Ley se exige la asunción por el concesionario del riesgo operacional, sin matices, no de un riesgo operacional [artículos 250.1.m), 258.b), 265.2, 285.1.c)], sin tener en cuenta esa posibilidad reconocida en la Directiva y subrayada, por ejemplo, en Alemania, de que la transferencia del riesgo al concesionario sea sólo parcial.

Como no es necesario que el concesionario asuma todo el riesgo, incluido el de demanda, siendo suficiente la asunción del riesgo de suministro, la LCSP permite expresamente que el concesionario sea retribuido mediante «pagos por disponibilidad» independientes de la demanda (art. 267, para la concesión de obra $)^{60}$. En cambio, no está prevista para la concesión de servicios (art. 289). Como se ha dicho, ese diferente trato carece de justificación, porque tanto en las concesiones de obras como en las de servicios es suficiente la asunción del riesgo de suministro ${ }^{61}$. Puede que el origen de esta diferencia normativa se encuentre en las reglas SEC-2010, que, como he explicado, están pensando siempre en contratos con un «activo» (una obra) que es necesario financiar. Sin embargo, la Directiva incorpora la regulación del riesgo de demanda y el de disponibilidad a todas las concesiones, sin distinción alguna, y no cabe distinguir allí donde la norma que se está tratando de incorporar no lo hace. Parece que la Ley, sin duda no por casualidad, ha querido terciar en la cuestión discutida sobre la relación entre «riesgo de suministro» y «riesgo de disponibilidad», admitiendo expresamente las concesiones de obra con pagos por disponibilidad (es decir, sin riesgo de demanda), que es probablemente el supuesto más discutible y también el que tendría más acogida en el mercado, lo que ya ha sido objeto de crítica ${ }^{62}$. Como he dicho supra, para sostener que el riesgo de suministro es algo más que el riesgo y ventura que asume todo contratista, hay que entenderlo en el sentido de que el concesionario asume el riesgo de que, como consecuencia de un exceso de demanda, y aunque él esté cumpliendo correctamente el contrato, se produzcan denegaciones de uso de la obra o servicio o no se cumplan los estándares de calidad y disponibilidad (embotellamientos, listas de espera, etc.).

En todo caso, creo que esa diferencia entre los artículos 267 y 289 debería ser irrelevante en la práctica, porque tanto uno como otro son innecesarios para desplegar las potencialidades que para la configuración del contrato se derivan del artículo 14.4. Dicho de otro modo, aunque no existiera ninguno de esos dos preceptos, a partir de la regulación general del riesgo operacional, podría haber concesiones sin asunción del riesgo de demanda, en las que, por tanto, se prevean pagos no ligados a la utilización o demanda de la obra o servicio, sino al riesgo de suministro ${ }^{63}$.

Por último, es necesario hacer referencia a esas otras previsiones de los contratos de concesión, que son ciertamente ajenas a las obligaciones básicas de las partes que son las que definen su estructura, pero que contribuyen a definir la atribución o transmisión de riesgos, hasta el punto de haber provocado en algunos casos, como vimos en el epígrafe 4, un cambio en la clasificación contable de algunas concesiones.

En este punto la LCSP intenta evitar que por la vía de los preceptos sobre la ejecución del contrato se incumpla la transferencia del riesgo, dando lugar a que el contrato deje de ser concesión y que la inversión consolide como déficit y deuda. Así, se excluye expresamente que el incumplimiento de las previsiones de demanda sea causa que justifique el restablecimiento del equilibrio económico (artículo 270.2, último

exposición real a las incertidumbres del mercado que implique que cualquier pérdida potencial estimada en que incurra el concesionario no es meramente nominal o desdeñable».

60 «La retribución por la utilización de la obra podrá ser abonada por la Administración teniendo en cuenta el grado de disponibilidad ofrecido por el concesionario y/o su utilización por los usuarios, e la forma prevista en el PCAP. En caso de que la retribución se efectuase mediante pagos por disponibilidad deberá preverse en los pliegos de cláusulas administrativas particulares la inclusión de índices de corrección automáticos por nivel de disponibilidad independientes de las posibles penalidades en que pueda incurrir el concesionario en la prestación del servicio».

${ }^{61}$ Las observaciones del Observatorio de Contratación Pública sobre el Proyecto de Ley (que ya incluía estos dos preceptos, aunque con otra numeración) incidían en esta cuestión: «Se propone revisar los arts. 265.4 (concesión de obra) [actual artículo 267] y 287 (concesión de servicio) [actual artículo 289] para adecuarlos a la Directiva 2014/23 en materia de transferencia de riesgo operacional. Se propone la eliminación de la referencia a la "disponibilidad" en el art. 265.5 y su sustitución por "suministro" e introducir una referencia al "riesgo de suministro" en el art. 287. Es imprescindible que el tipo concesional sea coherente con la Directiva europea (la transferencia del riesgo es el elemento medular del tipo) y además no parece justificable introducir diferenciaciones entre la concesión de obras y la concesión de servicios ya que el legislador europeo exige en ambos casos la transferencia del riesgo (suministro y/o demanda)».

62 Vid., desde una perspectiva económica, G. LLOBET, "De los creadores de las radiales... Ilegan los pagos por disponibilidad" (20 de septiembre de 2017), http://nadaesgratis.es/gerard-Ilobet/de-los-creadores-de-las-radiales-Ilegan-los-pagos-por-disponibilidad.

${ }_{63}$ Un planteamiento opuesto al que se hacía en interpretación de la Ley de concesiones de obra de 2003: «El riesgo y ventura determina en definitiva que el concesionario dependa sustancialmente de los ingresos que obtenga por las tarifas que cobre a los usuarios que utilicen las infraestructuras» [F. SANZ GANDÁSEGUI, "El concepto de contrato de concesión de obras públicas", en A. MENÉNDEZ MENÉNDEZ (Dir.), Comentarios a la nueva Ley 13/2003, de 23 de mayo, reguladora del contrato de concesión de obras públicas, Civitas, Madrid, 2003, págs. 81-108, pág. 101]. 
párrafo). Vemos cómo una norma de transparencia contable, como las reglas SEC-2010, interfiere sobre la aplicación de reglas sustantivas como el rebus sic stantibus.

En la misma línea, los artículos 281 y 295 regulan los efectos de la resolución de los contratos de concesión en los mismos términos de la reforma introducida por la Ley 40/2015, es decir, limitando la «responsabilidad patrimonial administrativa» a los supuestos de resolución por causa imputable a la Administración concedente. Sin embargo, se mantiene la regla que permite limitar por encima y por debajo los ingresos del concesionario, cambiando las tarifas cuando la demanda supera un determinado nivel o no lo alcance [artículo 250.1.d)], a pesar de que como hemos visto puede plantear problemas desde el punto de vista de SEC-2010.

La LCSP hace, así, una transposición leal de la Directiva, en términos generales. Como no puede ser de otro modo, el nivel de riesgo que debe asumir el concesionario es menor de lo que se pensaba en la Ley 13/2003 (aunque ésta acompañaba la transmisión del riesgo de demanda, que se daba por supuesta, con la aplicación general de la «responsabilidad patrimonial administrativa», que alteraba el nivel de riesgo de forma significativa). Los cambios son más aparentes que reales, porque ya se venían licitando concesiones en las que el concesionario no asumía el riesgo de demanda.

Esa incorporación de las categorías de la Directiva ha provocado que pierda toda relevancia, como criterio de distinción entre el contrato de servicios y la concesión de servicios, el hecho de que el servicio gestionado tenga -o no- la naturaleza de servicio público. Tanto la concesión como el contrato de servicios pueden referirse a la gestión de un servicio público o de un servicio que no tenga esa condición. De ahí que el régimen de ambos contratos se desdoble, con algunas normas especiales para el caso de que tenga por objeto un servicio público (artículos 284.2 y 312). Aunque el cambio haya sido polémico, creo que no habría tenido demasiado sentido una transposición que borrase la distinción entre las categorías utilizadas por las Directivas, es decir, una transposición en la que también se llamase «concesión» a algunos contratos que las Directivas califican como contratos de servicios. Y ello aun suponiendo que el régimen aplicable a esas «concesiones» cumpliera todos los requisitos exigidos por el Derecho comunitario a los contratos de servicios ${ }^{64}$.

\section{DUDAS Y CUESTIONES ABIERTAS}

Cabe plantearse, en primer lugar, si está garantizada la coordinación entre las normas de contratación pública (LCSP) y las normas contables (SEC-2010), de tal modo que todo contrato correctamente licitado y adjudicado como concesión, vaya a ser tratado contablemente de ese modo, es decir, sin imputar el montante total de la inversión al déficit público y a la deuda pública. La respuesta es que la Directiva ha intentado (sin decirlo) coordinarse con las reglas SEC-2010 (hasta cierto punto, porque se habla de «riesgo de suministro», no de "disponibilidad»), pero que no está garantizado que en el futuro la interpretación de los conceptos de ambas normas vaya a permanecer unida. Lo normal es que los contratos que la LCSP considere concesiones lo sean también a efectos contables, aunque no es totalmente seguro porque se trata de normas paralelas, no sometidas jerárquicamente una a otra.

También conviene preguntarse si el legislador podía haber ido más allá y exigir que el concesionario asuma más riesgos, por ejemplo para evitar que los poderes públicos tengan que asumir obligaciones económicas importantes si el negocio concesional fracasa. En mi opinión sí, porque la Directiva 2014/23 sólo exige que las Directivas se liciten por un procedimiento determinado (que es un procedimiento de mínimos) y que todo lo que no sean concesiones se licite por el procedimiento previsto en la Directiva 2014/24. Pero no impide que un Estado regule su actividad contractual, limitando el uso de determinados tipos contractuales o reduciendo su ámbito frente al que la Directiva contempla.

Pero la cuestión abierta más importante es la que se refiere a la definición del «riesgo de suministro» y su distinción respecto al «riesgo y ventura». Los órganos consultivos españoles ya venían interpretando la jurisprudencia comunitaria en el sentido de exigir «algo más» que el principio de riesgo y ventura, para que un contrato fuese calificado como concesión. Los resultados que se alcanzan en ese esfuerzo, cuando no incluyen la asunción del riesgo de demanda, no dejan de ser forzados, al sustantivar determinados riesgos

${ }^{64}$ La crítica a la nueva tipología, asumida por el Dictamen del Consejo de Estado de 10 de marzo de 2016, la desarrollan J. L. MARTÍNEZ ALONSO en "Modificación de la Ley de Contratos del Sector Público y gestión de servicios públicos locales: propuestas y alternativas", Revista General de Derecho Administrativo, 40 (2015), y F. HERNÁNDEZ GONZÁLEZ, "La controvertida supresión del contrato de gestión de servicios públicos", El Cronista, 60 (2016), págs. 50-57. 
(como el de insolvencia de los ciudadanos que tienen que pagar el coste del servicio) que no tienen verdadera entidad y que parecen servir fundamentalmente para justificar la calificación del contrato como concesión. Ya hemos visto la posible interpretación integradora que supone que el concesionario asume el riesgo de que por un incremento de la demanda, se produzcan denegaciones de uso o no se alcancen los estándares de calidad estipulados.

Aun teniendo en cuenta esta interpretación, una concesión basada sólo en la asunción del riesgo de disponibilidad tiene poco que ver con la concesión tradicional en la que el concesionario asumía el «riesgo de explotación de la obra». Si entendemos el «riesgo de suministro» como equivalente, más o menos, al de disponibilidad, llegamos a un resultado que no es muy diferente del que asumen muchos contratistas de servicios, que tienen obligaciones similares (garantizar que la obra o el servicio se preste en las condiciones de calidad, continuidad, etc., fijadas en el contrato) y cuya remuneración depende del cumplimiento de esas obligaciones, sin tener garantizada la recuperación de sus costes.

En definitiva, asistimos a una desnaturalización del concepto de concesión por razones puramente financieras (rectius, contables). Esa desnaturalización ya comenzó con el «peaje en sombra», pues a partir de ese momento la concesión pierde la que constituía su característica principal, que consiste en que el coste de la obra no lo asuma la Administración, sino los usuarios ${ }^{65}$. La concesión ya no sirve para ahorrar costes a la Administración, sino para que esos costes se reflejen de otro modo en la contabilidad. Si el concesionario asume el riesgo de demanda, la concesión con «peaje en sombra» se convierte, además, en un juego de azar, en el que la Administración puede «perder» o "ganar» en comparación con lo que le habría costado ese mismo activo a través de un contrato de obra (más la correspondiente financiación mediante deuda pública). Si esa misma concesión se basa en «pagos por disponibilidad», tiene de concesión poco más que el nombre, al que se saca partido a efectos financieros.

Por otro lado, recordemos que la exigencia de mayor o menor asunción de riesgos por parte del concesionario, más que señalar lo que se puede y lo que no se puede hacer, marca el límite entre dos contratos, la concesión y el contrato de servicios (o el de obra). Lo que no quepa en el contrato de concesión podrá rescatarse en otros contratos, especialmente en el de servicios, cuya regulación ya se ha modificado en esta línea, porque al quitar corsés sobre el plazo se ha querido ofrecer una «pista de aterrizaje» a aquellos proyectos que no quepan en el contrato de concesión pero exijan un plazo largo para la amortización de las inversiones.

Esta desnaturalización de los tipos contractuales, dirigida a aprovechar al máximo las técnicas de financiación privada y sobre todo para exprimir los límites de déficit y deuda, obligan a reaccionar, en mi opinión, en los procedimientos de aprobación de proyectos, para vigilar el principio de eficiencia (estas fórmulas pueden acabar siendo muy caras) y porque ya no podemos partir de que la concesión supone que el riesgo lo asume el concesionario.

65 Lo expresa con toda claridad R. GÓMEZ-FERRER MORANT: «la verdadera naturaleza de este caso es la de un contrato de obra pública con un sistema de retribución por la Administración aplazado en el tiempo y calculado en función del uso de la infraestructura en forma similar al de la concesión (peaje en la sombra)» ("El contrato de concesión de obras públicas: disposiciones generales", en la obra por él dirigida, Comentario a la Ley de Contratos de las Administraciones Públicas, Civitas, Madrid, $2004,2 .^{a}$ ed., págs. 1.085-1.204, pág. 1.105). 